\title{
Cocaine Acts as an Apparent Competitive Inhibitor at the Outward- Facing Conformation of the Human Norepinephrine Transporter: Kinetic Analysis of Inward and Outward Transport
}

\author{
Nianhang Chen ${ }^{1,2}$ and Joseph B. Justice $\mathrm{Jr}^{2}$ \\ 'Department of Pharmacology, Nanjing Medical University, Nanjing 210029, People's Republic of China, and \\ 2Department of Chemistry, Emory University, Atlanta, Georgia 30322
}

The inhibition by cocaine of inward and outward transport of dopamine (DA) at the cloned human norepinephrine transporter (hNET) and the relationship of the inhibitory patterns of cocaine to the conformational requirements of the transporter were investigated. This was done using rotating disk electrode voltammetry in transfected cells. The uphill uptake of external DA, the lack of inhibition by internal substrates on DA uptake, and the accelerated exchange of internal DA by external $m$-tyramine support a carrier model in which the hNET alternates between outward-facing and inward-facing conformations. Cocaine exhibited competitive inhibition of DA uptake, which was insensitive to intracellular substrates. In contrast, the inhibition by cocaine of the $m$-tyramine-induced DA efflux appeared noncompetitive relative to intracellular DA, but competitive relative to extracellular $m$-tyramine. Simultaneous measurement of $m$-tyramine uptake and accompanying DA efflux at various concentrations of intracellular DA showed that cocaine did not alter the ratio of DA efflux to $m$-tyramine uptake. Moreover, cocaine displayed similar potency for inhibiting DA uptake and efflux. Additionally, the inhibition profile of cocaine was unrelated to the addition time of cocaine, simultaneously with or earlier than a substrate. All of the findings are consonant with a competitive interaction between cocaine and substrates at the outward-facing conformation of the hNET. This action directly prevents the inward transport of external substrates, thereby inhibiting the outward transport of internal substrates by reducing the availability of the inward-facing conformation. Consequently, the experimental inhibition pattern of cocaine depends on the conformation of the hNET to which the transported substrate is exposed.

Key words: cocaine; dopamine; m-tyramine; norepinephrine transporter; rotating disk voltammetry; uptake; efflux; kinetic analysis
The norepinephrine transporter (NET) mediates uptake of synaptic norepinephrine (NE) into NE neurons. It also transports structurally similar substrates including dopamine (DA), tyramine, and amphetamine (Bönisch and Brüss, 1994; Gu et al., 1994; Burnette et al., 1996; Justice et al., 1998). In the conventional model for monoamine transporters, it is assumed that the transporter alternates between its outward and inward facing conformations (Rudnick, 1997). The outward-facing conformation exposes the substrate site to the outside face of the membrane, and the inward-facing conformation exposes the substrate site to the inside face of the membrane. Like other members of monoamine transporter family, the NET uses the energy of the transmembrane $\mathrm{Na}^{+}$gradient to drive the accumulation of a substrate inside the cell (Bönisch and Brüss, 1994; Gu et al., 1996). However, a reversal of transport direction can be induced by inward transport of any substrate (Langeloh et al., 1987; Levi and Raiteri, 1993; Burnette et al., 1996; Chen et al., 1998).

The psychostimulant cocaine interacts with NET as an effective inhibitor both in vivo (Chen and Reith, 1994, 1995) and in vitro (Graefe and Bönisch, 1988; Pacholczyk et al., 1991; Gu et al.,

\footnotetext{
Received May 18, 1998; revised Sept. 23, 1998; accepted Sept. 25, 1998.

This study was supported by National Institute on Drug Abuse (NIDA) Grant R03 DA10896. J.B.J. is a recipient of an NIDA Research Scientist Award (K02 DA00179). We thank Brian Reed for help with the two-electrode voltammetry experiments.

Correspondence should be addressed to Dr. Nianhang Chen, Department of Chemistry, Emory University, Atlanta, GA 30322-2210.

Copyright (C) 1998 Society for Neuroscience $0270-6474 / 98 / 1810257-12 \$ 05.00 / 0$
}

1994; Masahiko et al., 1997). Although numerous functional studies have been performed to address the molecular mechanism of cocaine, there has been lack of agreement in the literature concerning the interactions between cocaine and substrates at catecholamine transporters. Earlier studies on isolated peripheral tissues reported that cocaine is a competitive inhibitor of the inward transport of $\left[{ }^{3} \mathrm{H}\right] \mathrm{NE}$ (Graefe and Bönisch, 1988) but is equally potent an inhibitor of zero-[ $\left[\mathrm{Na}^{+}\right]$-induced $\left[{ }^{3} \mathrm{H}\right] \mathrm{NE}$ efflux when the tissue is preloaded with either low or high concentration of $\left[{ }^{3} \mathrm{H}\right] \mathrm{NE}$ (Graefe and Fuchs, 1979), resembling a noncompetitive pattern. Analogously, the discrepancy has also been observed in studies on the inhibition by cocaine of another catecholamine transporter, the dopamine transporter (DAT). In those studies with brain tissue or synaptosomes, all patterns of inhibition have been reported: competitive, noncompetitive, and uncompetitive (Krueger, 1990; McElvain and Schenk, 1992; Wheeler et al., 1994; Povlock and Schenk, 1997).

Catecholamine transporters are integral membrane proteins spanning the membrane and exposed on both sides of membrane. They are not symmetric in structure. Thus, cocaine, no matter how it approaches the transporter, from one side of the membrane or from both sides, raises the same question: on which transporter conformations does it act? Depending on the specificity of cocaine for inward-facing and outward-facing conformations, the inhibition pattern in different transport assays may vary from competitive to noncompetitive or mixed, as elucidated for simple facilitated transport (Krupka and Devés, 1983; Stein, 1986; Devés and Krupka, 1989). Accordingly, the inhibition pattern 
observed in a particular type of experiment may not reflect the actual mechanism. Identification of the transporter conformational requirement of the action of cocaine is necessary to distinguish the mechanism of cocaine from its multiple inhibitory patterns.

In the present study, we performed kinetic analyses on inward and outward DA transport via the human NET (hNET) to probe the mechanism of cocaine. Two interrelated questions are addressed. First, what is the real nature of the interaction between cocaine and substrate at the hNET: competitive, noncompetitive, or uncompetitive? Second, which conformation of the hNET does cocaine attack: outward-facing, inward-facing, or both? The results strongly suggest that cocaine interacts competitively with the outward-facing conformation of the hNET.

\section{MATERIALS AND METHODS}

Materials. Dopamine hydrochloride, cocaine hydrochloride (COC), ouabain, $\left[{ }^{3} \mathrm{H}\right] \mathrm{H}_{2} \mathrm{O}(1.0 \mathrm{mCi} / \mathrm{gm})$, and $\left[{ }^{14} \mathrm{C}\right]$ inulin $(1.4 \mathrm{mCi} / \mathrm{gm})$ were from Sigma (St, Louis, MO). $m$-Tyramine ( $m$-TYR) was from Research Biochemicals (Natick, MA). The LLC-PK 1 cell stably expressing the human NE transporter (LLC-hNET) was a gift from Dr. Gary Rudnick (Department of Pharmacology, Yale University). Because DA is more stable at physiological $\mathrm{pH}$ than $\mathrm{NE}$, we chose to use DA as a substrate of the hNET throughout the transport assays.

Preparation of cell suspension. The culture of LLC-hNET cells and the preparation of the cell suspensions were performed as described previously (Chen et al., 1998). The assay buffer contained (in mM) $120 \mathrm{NaCl}$, $4.7 \mathrm{KCl}, 2.2 \mathrm{CaCl}_{2}, 1.2 \mathrm{MgSO}_{4}, 1.2 \mathrm{KH}_{2} \mathrm{PO}_{4}, 10 \mathrm{HEPES}$, and 10 glucose, $\mathrm{pH} 7.4$.

Determination of DA content inside cells. Cells were incubated with varying concentrations of DA under the same conditions as for rotating disk electrode (RDE) voltammetry experiments for 5-20 min. At each tested time, an aliquot $(60 \mu \mathrm{l})$ of the cell suspension was quickly transferred to a vial containing $1 \mathrm{ml}$ ice-cold assay buffer and centrifuged at $2000 \times g$ for $1 \mathrm{~min}$. The supernatant was removed and acidified by 1:10 volume of $0.1 \mathrm{M}$ perchloric acid, and the cells were lysed in $200 \mu \mathrm{l} 0.1 \mathrm{M}$ perchloric acid. Samples of the supernatants and cell extracts were analyzed for DA content by microbore HPLC with electrochemical detection as described previously (Chen et al., 1998).

Assay of intracellular water space. Cells ( $\sim 2 \mathrm{mg}$ cell protein per assay) were suspended in the assay buffer and incubated for $10 \mathrm{~min}$ at $37^{\circ} \mathrm{C}$ with $\left[{ }^{3} \mathrm{H}\right] \mathrm{H}_{2} \mathrm{O}(1.5 \mu \mathrm{Ci} / \mathrm{ml})$ and $\left[{ }^{14} \mathrm{C}\right]$ inulin $(0.3 \mu \mathrm{Ci} / \mathrm{ml})$ in a final volume of $1 \mathrm{ml}$. The cell pellets were collected by centrifugation at $1000 \times g$ for 2 min and then lysed by $400 \mu \mathrm{l}$ Triton X-100 $(0.1 \%$ in $5 \mathrm{~mm}$ Tris- $\mathrm{HCl}, \mathrm{pH}$ 7.4). The radioactivity of samples was measured by liquid scintillation counting. Intracellular water space was calculated as the difference between total $\left[{ }^{3} \mathrm{H}\right] \mathrm{H}_{2} \mathrm{O}$ space and extracellular $\left[{ }^{14} \mathrm{C}\right]$ inulin space and expressed as microliter of cell water per milligram of protein.

Measurement of rotating disk electrode voltammetry. For one-electrode voltammetry, a Teflon-shielded glassy carbon working electrode (electrode 1, $3 \mathrm{~mm}$ diameter; Pine Instrument Company, Grove City, PA) was mounted at the top of an electrochemical cell. An LC-4 Amperometric Detector (Bioanalytical Systems, Lafayette, IN) was used as a potentiostat, and the output current was amplified (model 427; Keithley Instruments, Cleveland, $\mathrm{OH}$ ). The potential of the working electrode was set at $+400 \mathrm{mV}$ relative to $\mathrm{Ag} / \mathrm{AgCl}$ reference electrode. For twoelectrode voltammetry, a second Teflon-shielded glassy carbon working electrode (electrode 2, $3 \mathrm{~mm}$ diameter) was fitted at the bottom of the electrochemical cell. A dual channel microelectrode potentiostat (model EI-400; Ensman Instrumentation, Bloomington, IN) was used to control the potentials at the two separate working electrodes: $+400 \mathrm{mV}$ for electrode 1 , and $+650 \mathrm{mV}$ for electrode 2 . The resulting oxidative current corresponded to DA signal at $+400 \mathrm{mV}$ and corresponded to both DA and $m$-tyramine signals at $+650 \mathrm{mV}$. $m$-Tyramine was not oxidized at $+400 \mathrm{~mm}$. After the cell suspension was placed into the electrochemical cell, the electrode 1 was introduced just below the surface of the solution and rotated with an AFMSRX Analytical Rotator System (Pine Instrument Company). All experiments were performed at an electrode rotation rate of $4000 \mathrm{rpm}$ at $37^{\circ} \mathrm{C}$. Origin software (version 4.0; MicroCal Software, Northampton, MA) was used for data acquisition as described previously (Burnette et al., 1996; Chen et al., 1998)

Transport assays. In transport assays, cocaine was added either simul- taneously with, or 6 min earlier than a substrate, and the initial transport rate over the first $10-15 \mathrm{sec}$ was measured. The simultaneous addition partially restricted cocaine outside the cell, whereas the previous addition allowed cocaine to equilibrate across the membrane during the assay. Comparison of results from both approaches allowed evaluation of the relative contribution of external and internal cocaine to the observed inhibition profile.

For uptake assays, cells were preincubated for 3-5 min and then 1 min baseline was collected. Subsequently, DA was added to the cell suspension, and the decrease in the DA signal was recorded. In some experiments, cells were preincubated with or without $3 \mu \mathrm{M} \mathrm{m}$-tyramine in parallel at $37^{\circ} \mathrm{C}$ for $8 \mathrm{~min}$. The incubation was terminated by centrifugation at $1000 \times g$ for $2 \mathrm{~min}$. The resulting cell pellet was resuspended in assay buffer and then used for uptake assays.

For efflux assays, cells were incubated with DA until the DA signal decreased to a steady state. Subsequently, $m$-tyramine was added and the increase in DA signal corresponding to this addition was recorded until the signal ceased to increase. In the presence of cocaine, $m$-tyramineinduced DA efflux was defined as the difference between the total DA efflux in the presence of $m$-tyramine plus cocaine and the nonspecific DA efflux in the presence of cocaine alone. The nonspecific DA efflux in the presence of varying concentrations of cocaine at several fixed concentrations of preloaded DA was separately determined in close generations of cells. The Michaelis-Menten equation expressing the relationship between the nonspecific DA efflux and [cocaine] at a fixed initial medium $[\mathrm{DA}]\left([\mathrm{DA}]_{\mathrm{o}}\right.$ ) was obtained by nonlinear fitting the data as a function of [cocaine] $(3-300 \mu \mathrm{M})$. The linear regression equation expressing the relationship between the nonspecific DA efflux and initial $[D A]_{0}$ at a fixed [cocaine] was obtained by fitting the data as a function of initial [DA] $(0.5-4 \mu \mathrm{M})$. The nonspecific DA efflux rate at a particular combination of [cocaine] and initial $[\mathrm{DA}]_{\mathrm{o}}$ was estimated according to the related equations. Parallel measurements of the nonspecific DA efflux were included periodically in the DA efflux assays, which gave values similar to those estimated from the equations.

For simultaneous monitoring of $m$-tyramine uptake and DA efflux, cells were incubated with DA until the DA signal decreased to a steady state. Subsequently, $m$-tyramine $(3 \mu \mathrm{M})$ was added. The increase in the DA signal at electrode 1 and the signal change at electrode 2 (a combination of increased DA signal and reduced $m$-tyramine signal) were recorded simultaneously until the DA efflux signal reached its maximum. DA signal at electrode 1 was subtracted from the mixed signal at electrode 2 to give the $m$-tyramine signal. Because $m$-tyramine itself caused a small signal decay by filming at the surface of the electrode, the signal decay specifically for hNET-mediated $m$-tyramine uptake was defined as the difference between the signal decay in the absence and presence of $100 \mu \mathrm{M}$ cocaine.

Data analysis and statistics. Initial transport rates were obtained from linear regression analysis of the $[\mathrm{DA}]_{\mathrm{o}}$ or medium $[m$-tyramine $]$ ([mtyramine $]_{\mathrm{o}}$ ) versus time over the first $10-15 \mathrm{sec}$ after an addition as described previously (Burnette et al., 1996; Chen et al., 1998). EadieHofstee transformation of the Michaelis-Menten equation was used to assess the apparent inhibition patterns of cocaine on the velocity of DA transport. The maximal rate of transport $\left(V_{\max }\right)$ and the half-saturation concentration of a substrate $\left(K_{\mathrm{m}}\right)$ were estimated by nonlinear curve fitting of the Michaelis-Menten equation to the rate data. If cocaine appeared as a competitive inhibitor of substrate transport, the halfsaturation inhibition constant $\left(K_{\mathrm{i}}\right)$ was estimated by fitting with the equation $K_{\mathrm{m} \text { obs }}=K_{\mathrm{m}}\left(1+\right.$ [cocaine] $\left./ K_{\mathrm{i}}\right)$. Here $K_{\mathrm{m} \text { obs }}$ and $K_{\mathrm{m}}$ are the concentrations of a substrate to produce $50 \%$ of its maximal transport rate in the presence and absence of cocaine, which were determined in parallel. In experiments to address the effect of various concentrations of cocaine on the transport of a fixed concentration of a substrate, the competitive $K_{\mathrm{i}}$ of cocaine for inhibiting DA uptake and $m$-tyramineinduced DA efflux were analyzed according to the equation: $v / v^{\prime}=1+$ [cocaine $] /\left\{K_{\mathrm{i}}\left(1+[S] / K_{\mathrm{s}}\right)\right\}$, in which, $v$ and $v^{\prime}$ are the initial transport rate in the absence and presence of cocaine, respectively; $[S]$ is the concentration of the substrate (DA or $m$-tyramine); $K_{\mathrm{s}}$ is the half-saturation concentration of the substrate to be taken up or to induce DA efflux, and set at the average values determined from separate saturation curves. $\mathrm{IC}_{50}$ values of cocaine for inhibiting $m$-tyramine uptake and $m$-tyramineinduced DA efflux at each preloaded [DA] were computed by nonlinear curve fitting the efflux rate data as a function of [cocaine] with the logistic equation. This nonlinear regression program was run with the rate value at $[$ cocaine] $=0$ fixed at the tested value and the rate value at [cocaine] $=\infty$ fixed at zero. In experiments to simultaneously measure $m$-tyramine 
uptake and DA efflux, the ratio of DA efflux to $m$-tyramine uptake was fitted as a function of intracellular $[\mathrm{DA}]\left([\mathrm{DA}]_{\mathrm{i}}\right)$ using the equation: ratio $=[\mathrm{DA}]_{\mathrm{i}} /\left(K_{0.5}+[\mathrm{DA}]_{\mathrm{i}}\right)$, derived from the six state transport model (Justice and Reed, 1997). This equation can be rewritten as a special example of the Michaelis-Menten expression: ratio $=\left(R_{\max }[\mathrm{DA}]_{\mathrm{i}}\right) /\left(K_{0.5}\right.$ $\left.+[\mathrm{DA}]_{\mathrm{i}}\right)$, in which $R_{\max }$ is the maximal ratio and equal to 1 , and $K_{0.5}$ is the intracellular concentration of DA to produce half-maximal ratio. In the presence of cocaine $(3 \mu \mathrm{M})$, the predicted shift of the curve of DA efflux $/ m$-tyramine uptake ratio versus $[\mathrm{DA}]_{\mathrm{i}}$ was obtained as follows: (1) estimate the DA efflux solely caused by $m$-tyramine uptake by the equation efflux rate ${ }_{+\mathrm{COC}}$, estimated $=$ uptake rate ${ }_{+\mathrm{COC}}$, experimental $\times$ efflux rate ${ }_{-\mathrm{COC}}$, experimental $/$ uptake rate ${ }_{-\mathrm{COC}}$, experimental (2) fit the efflux rate $_{+ \text {Coc, estimated }}$ as a function of $[D A]_{i}$ to obtain its Michaelis-Menten expression; (3) predict the efflux rate in the presence of putative interaction of cocaine with internal DA (efflux rate + COC, predicted $)$ from the Michaelis-Menten expression of efflux rate $+\mathrm{COC}$, estimated modified for competitive, noncompetitive, and uncompetitive inhibitions (Stein, 1986) (the $K_{\mathrm{i}}$ of cocaine was set at $2 \mu \mathrm{M}$ ); and (4) estimate the predicted ratio by replacing the experimental DA efflux rate with predicted DA efflux rate from step 3 , that is, ratio $_{\text {predicted }}=$ efflux rate $+\mathrm{COC}$, predicted $/$ uptake rate

All curve fitting was done with the Origin nonlinear fitting and plotting software. All results were expressed as mean \pm SE. Statistics consisted of one-way ANOVA followed by the Newman-Keuls test and various Student's $t$ test, as appropriate. The accepted level of significance was 0.05 .

\section{RESULTS}

\section{Intracellular DA concentrations}

The intracellular water content of hNET-LLC cells was $3.17 \pm$ $0.16 \mu \mathrm{l} / \mathrm{mg}$ protein $(n=17)$. Intracellular DA concentrations were estimated according to the cellular DA content and the cell water space. The cellular DA levels were similar at 5 and $10 \mathrm{~min}$ after the addition of DA, and then they tended to decrease (Fig. $1 A$ ). Significant reduction in cellular DA levels was seen at $20 \mathrm{~min}$ after the addition of DA (Fig. $1 A$ ). This loss of internal DA was more appreciable at low initial $[\mathrm{DA}]_{\mathrm{o}}$ than higher initial $[\mathrm{DA}]_{\mathrm{o}}$ (Fig. $1 A)$. The COMT inhibitor tropolone $(1 \mathrm{mM})$ significantly increased the cellular DA level when initial [DA] o was $1 \mu \mathrm{M}$, indicating metabolism of intracellular DA by catechol- $O$ methyltransferase (COMT) (Eshleman et al., 1997; Chen et al., 1998). However, it had no effect on the cellular DA level when initial $[\mathrm{DA}]_{\mathrm{o}}$ was $6 \mu \mathrm{M}$ (data not shown), possibly because of the saturation of the COMT at higher internal DA concentrations. The DA level in cells incubated without DA was undetectable. The DA level in the wash supernatants was only detectable in assays with high initial $[\mathrm{DA}]_{\mathrm{o}}(4-6 \mu \mathrm{M})$, and was $<30 \mathrm{~nm}$.

Over the range of initial $[\mathrm{DA}]_{\mathrm{o}}$ tested $(0.5 \mu \mathrm{M}-6 \mu \mathrm{M})$, the $[D A]_{0}$, measured by RDE voltammetry, decreased to its steady state within 3-10 min after its addition. At the steady state, [DA] varied from 24 to $700 \mathrm{~nm}$, whereas $[\mathrm{DA}]_{\mathrm{i}}$ varied from 44 to 517 $\mu \mathrm{M}$. Comparisons of $[\mathrm{DA}]_{\mathrm{o}}$ and $[\mathrm{DA}]_{\mathrm{i}}$ at the steady state indicate that the hNET builds up a 700-1800-fold DA gradient across the membrane. Within a time range comparable to that for the RDE voltammetry experiments (maximal $20 \mathrm{~min}$ ), the $[\mathrm{DA}]_{\mathrm{i}}$ was linear with the initial $[\mathrm{DA}]_{\mathrm{o}}$ (Fig. $1 B$ ). To ensure maximal uptake of extracellular DA and minimal degradation of intracellular DA in the efflux experiments, we initiated DA efflux by adding $m$-tyramine between 5 and $10 \mathrm{~min}$ after the addition of DA, during which the steady state of $[\mathrm{DA}]_{\mathrm{o}}$ was established, and the $[D A]_{i}$ was relatively stable. The linear regression equation, obtained from plotting $[\mathrm{DA}]_{\mathrm{i}}$ at $10 \mathrm{~min}$ after the addition of DA as a function of initial $[\mathrm{DA}]_{\mathrm{o}}$ (Fig. $1 B$ ), was used to estimate the intracellular DA concentrations in all efflux experiments.
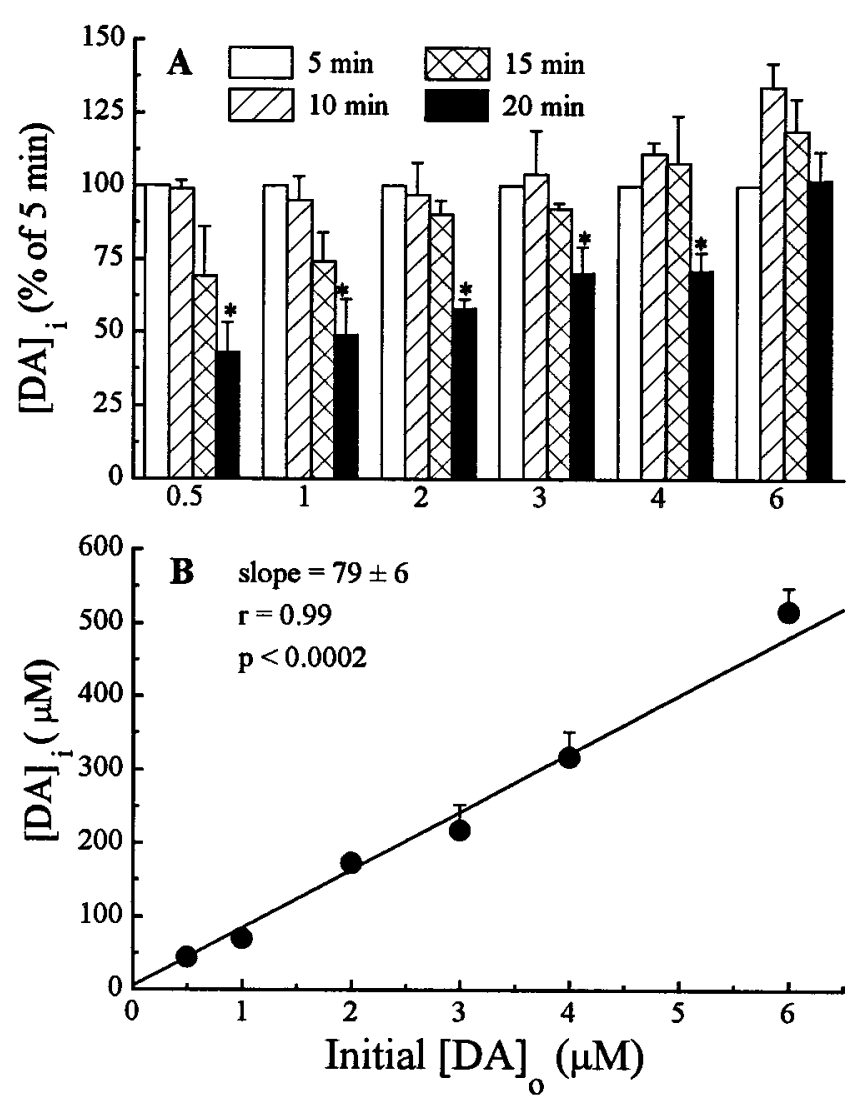

Figure 1. Relationship of intracellular DA concentration with time and initial medium DA concentrations. $A$, Change in $[\mathrm{DA}]_{\mathrm{i}}$ with the incubation time at each initial $[\mathrm{DA}]_{\mathrm{o}}$. Data are presented as percentage of the $[\mathrm{DA}]_{\mathrm{i}}$ at $5 \mathrm{~min}$. Intracellular DA degradation was significant at $20 \mathrm{~min}$, especially when the initial $[\mathrm{DA}]_{\mathrm{o}}$ was lower. $B$, Linear relationship between $[\mathrm{DA}]_{\mathrm{i}}$ and initial $[\mathrm{DA}]_{\mathrm{o}}$ at $10 \mathrm{~min}$. The straight line represents the result of the least squares linear regression. Similar linear relationships were observed at 5,15 , and $20 \mathrm{~min}$ with slopes being $65 \pm 2,76 \pm 4$, and $62 \pm 4$, respectively $(r=0.99 ; p<0.0001$ at each time point). Values are mean $\pm \mathrm{SE}$ of four experiments, each of which was performed with six concentrations of DA and four time points on the same generation of cells. ${ }^{*} p<0.05$ versus the $100 \%$ at 5 min (one sample $t$ test).

\section{Saturation kinetic characteristics of inward and outward transport of dopamine}

For DA dependence of the transport, the initial rates of DA uptake and subsequent $m$-tyramine $(10 \mu \mathrm{M})$-induced DA efflux were measured in the same cell suspensions. DA transport was saturable and followed the hyperbolic relationship described by Michaelis-Menten kinetics (Fig. 2A, B). The Hill slopes were $0.88 \pm 0.1$ for DA uptake, and $1.08 \pm 0.07$ for DA efflux. Although the $V_{\max }$ values were similar between inward and outward transport of DA, the $K_{\mathrm{m}}$ for $m$-tyramine-induced DA efflux was much higher than that for DA uptake $(0.88$ and $396 \mu \mathrm{M}$, respectively, Fig. $2 A, B)$.

For $m$-tyramine dependence of the outward DA transport, the cells was preloaded with $84 \mu \mathrm{M}$ DA (resulting from an incubation of cells with $1 \mu \mathrm{M}[\mathrm{DA}]_{\mathrm{o}}$ ) and DA efflux was induced by various initial medium concentrations of $m$-tyramine. The efflux rate was also saturable with initial [ $m$-tyramine $]_{0}$ and well fitted by the Michaelis-Menten expression (Fig. 2C). The Hill slope was $1.11 \pm 0.06$. The $K_{\mathrm{m}}$ value for $m$-tyramine to induce DA efflux was similar to its $K_{\mathrm{i}}$ to inhibit DA uptake (1.95 \pm 0.16 vs $1.63 \pm$ $0.22 \mu \mathrm{M}, n=4)$. 

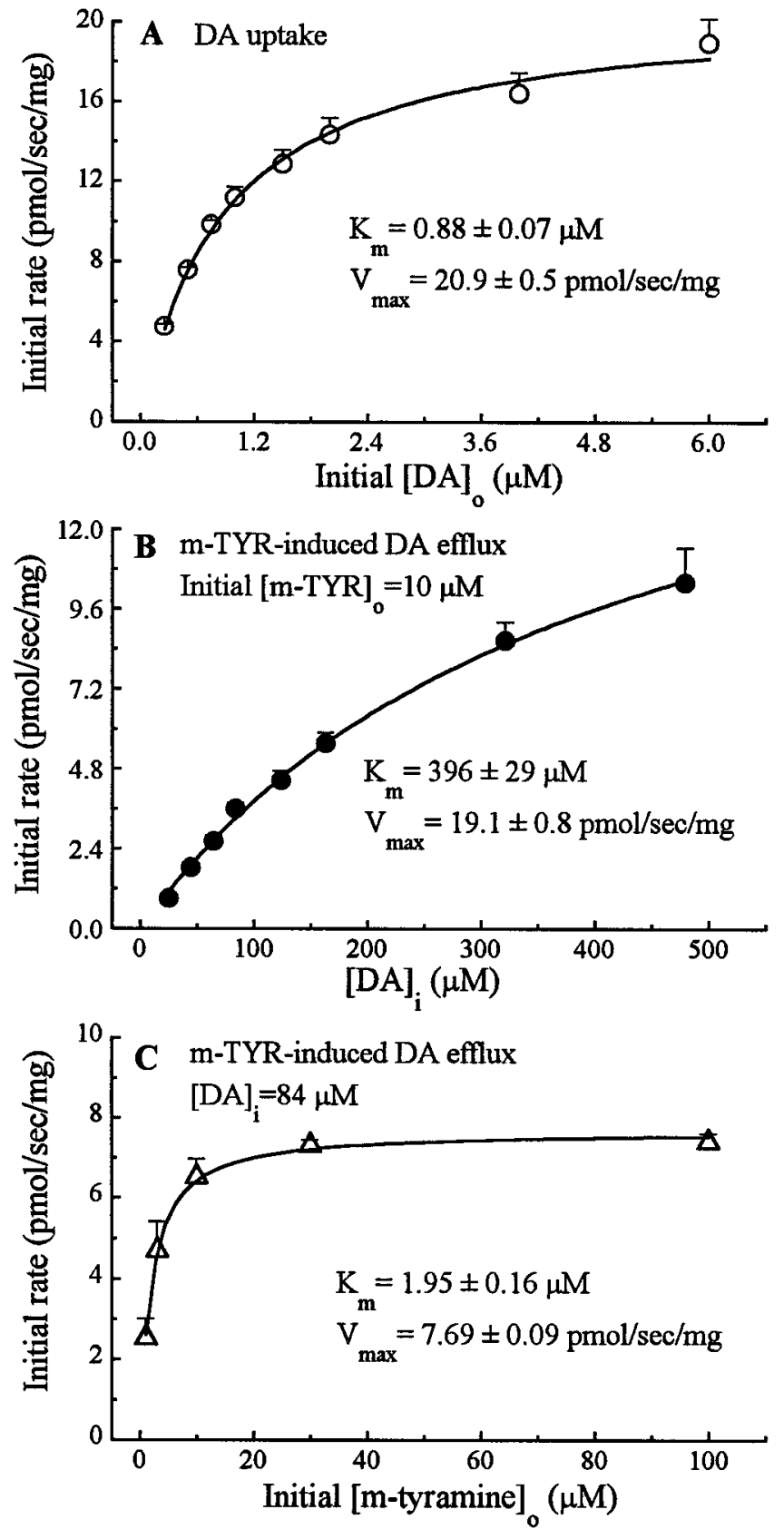

Figure 2. Hyperbolic relationships between the initial rate of the DA transport and the substrate concentration. For DA dependence of the transport, the initial rate of DA uptake and subsequent $m$-tyramineinduced DA efflux were measured in the same cell suspensions. The DA efflux was initiated by $m$-tyramine $(m-T Y R)$ after [DA] decreased to the steady state. Additions of DA or $m$-tyramine were made at one concentration per cell suspension. The solid curve was fit by the MichaelisMenten equation. $A$, Dependence of the DA uptake on the initial $[\mathrm{DA}]_{\mathrm{o}}$. $B$, Dependence of the $m$-tyramine-induced DA efflux on $[\mathrm{DA}]_{\mathrm{i}}$ at a fixed initial $[m \text {-tyramine }]_{\mathrm{o}}(10 \mu \mathrm{M})$. Note that the $K_{\mathrm{m}}$ relative to $[\mathrm{DA}]_{\mathrm{i}}$ is very high, although the $V_{\max }$ is close to that for DA uptake. $C$, Dependence of the $m$-tyramine-induced DA efflux on the initial $[m \text {-tyramine }]_{o}$ at a fixed $[\mathrm{DA}]_{\mathrm{i}}(84 \mu \mathrm{M})$. Values are mean $\pm \mathrm{SE}$ of three to six experiments, each of which was performed with eight concentrations of DA or five concentrations of $m$-tyramine on the same generation of cells.

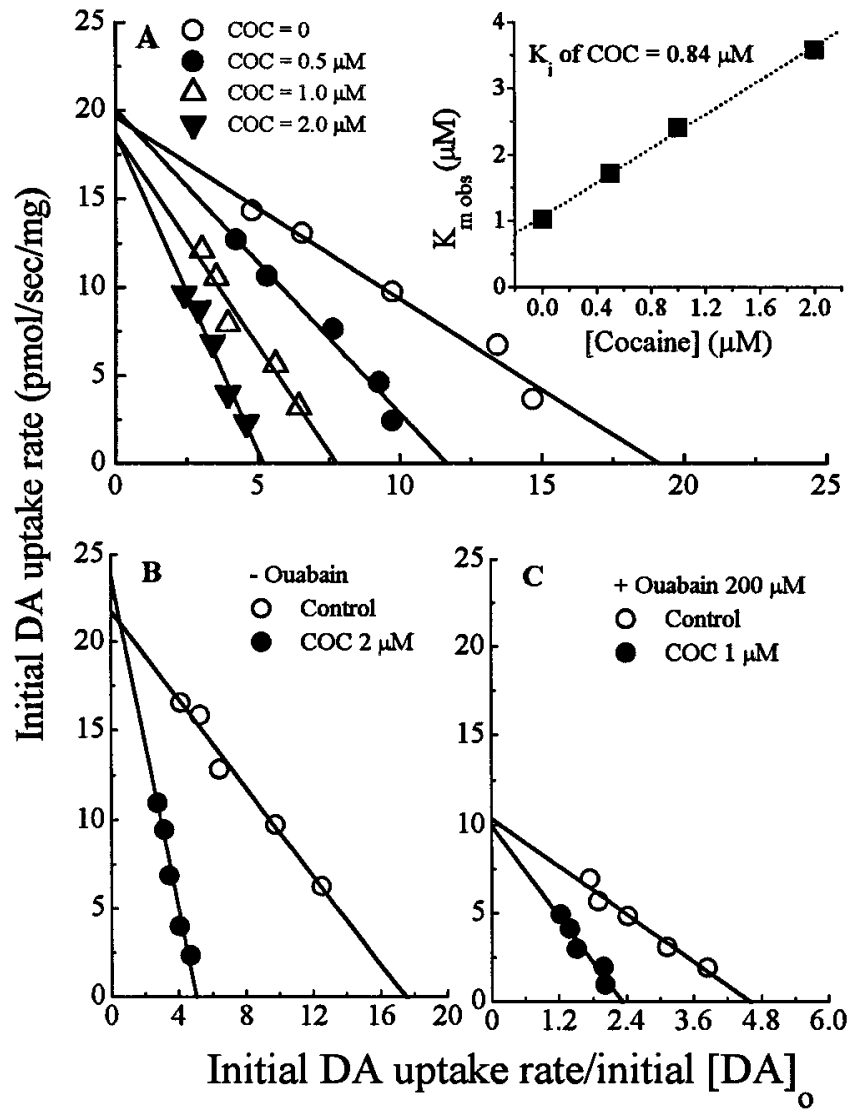

Figure 3. Competitive inhibition by cocaine $(C O C)$ of DA uptake. Eadie-Hofstee plots were used to analyze the inhibition patterns. The straight solid line represents the result of the least squares linear regression. Each panel shows a representative experiment with five levels of initial $[\mathrm{DA}]_{\mathrm{o}}$ and indicated levels of [cocaine] on the same generation of cells. Each experiment was performed three times with similar results. $A$, Effect of cocaine when added simultaneously with DA. Cocaine increased the $K_{\mathrm{m} \text { obs }}$ (slope of the curve) without changing the $V_{\max }$ ( $y$ intercept of the curve). Inset shows replot of $K_{\mathrm{m} \text { obs }}$ obtained from the Eadie-Hofstee plot as a function of the concentration of cocaine. The straight dotted line represents the predicted shift in $K_{\mathrm{m} \text { obs }}$ by the competitive model. $B$, Effect of cocaine when added 6 min earlier than DA. Earlier addition of cocaine did not change the inhibition pattern of cocaine. $C$, Effect of cocaine when added together with $200 \mu \mathrm{M}$ ouabain 6 min earlier than DA. Inactivation of $\mathrm{Na}^{+}, \mathrm{K}^{+}$-ATPase with ouabain inhibited the DA uptake in a mixed competitive and noncompetitive manner, with $K_{\mathrm{m}}$ increasing and $V_{\max }$ decreasing, but it did not change the inhibition pattern of cocaine. This experiment was run in parallel with the experiment in $B$.

\section{Effect of cocaine on inward transport of dopamine Cocaine added simultaneously with $\mathrm{D} A$}

To investigate the inhibition pattern of the external cocaine, cocaine was added simultaneously with DA to minimize the entry of external cocaine into cells during the early phase of DA uptake. Initial rates of DA transport into LLC-hNET cells devoid of endogenous substrates were determined at various concentrations of DA and cocaine in the medium. The Eadie-Hofstee plot of the data showed that the inhibition pattern of cocaine was competitive (Fig. $3 A$ ). It raised $K_{\mathrm{m}}$ with no change in $V_{\max }$ (Table $1)$. The observed $K_{\mathrm{m}}\left(K_{\mathrm{m} \text { obs }}\right)$ showed a high degree of linearity with [cocaine] (Fig. 3A, inset). The graphically estimated competitive $K_{\mathrm{i}}$ of cocaine was $0.79 \pm 0.04 \mu \mathrm{M}$, similar to the value of $0.82 \pm 0.02 \mu \mathrm{M}(n=4)$ determined from the separate inhibition curves of cocaine for the uptake of $1 \mu \mathrm{M}$ DA. 


\begin{tabular}{|c|c|c|c|c|c|c|}
\hline \multirow[b]{3}{*}{$\begin{array}{l}{[\text { Cocaine] }} \\
(\mu \mathrm{M}) \\
\end{array}$} & \multicolumn{2}{|c|}{ Added simultaneously } & \multicolumn{4}{|c|}{ Added 6 min earlier } \\
\hline & \multirow[b]{2}{*}{$K_{\mathrm{m} \text { obs }}(\mu \mathrm{M})$} & \multirow[b]{2}{*}{$\begin{array}{l}V_{\max \text { obs }} \\
(\mathrm{pmol} / \mathrm{sec} / \mathrm{mg})\end{array}$} & \multicolumn{2}{|l|}{ - Ouabain } & \multicolumn{2}{|c|}{+ Ouabain $200 \mu \mathrm{M}$} \\
\hline & & & $K_{\mathrm{m} \text { obs }}(\mu \mathrm{M})$ & $\begin{array}{l}V_{\max \text { obs }} \\
(\mathrm{pmol} / \mathrm{sec} / \mathrm{mg})\end{array}$ & $K_{\mathrm{m} \text { obs }}(\mu \mathrm{M})$ & $\begin{array}{l}V_{\max \text { obs }} \\
(\mathrm{pmol} / \mathrm{sec} / \mathrm{mg})\end{array}$ \\
\hline 0.0 & $1.06 \pm 0.09$ & $20.6 \pm 1.5$ & $1.18 \pm 0.08$ & $19.4 \pm 1.2$ & $1.85 \pm 0.21^{*}$ & $9.8 \pm 0.4^{*}$ \\
\hline 0.5 & $1.84 \pm 0.07 * *$ & $21.2 \pm 1.3$ & & & & \\
\hline 1.0 & $2.57 \pm 0.11^{* *}$ & $20.8 \pm 1.4$ & & & $4.88 \pm 0.53^{* *}$ & $10.9 \pm 0.6$ \\
\hline 2.0 & $3.90 \pm 0.18^{* *}$ & $19.9 \pm 1.1$ & $4.82 \pm 0.18^{* *}$ & $22.0 \pm 1.0$ & & \\
\hline$K_{\mathrm{i}}(\mu \mathrm{M})$ & \multicolumn{2}{|c|}{$0.79 \pm 0.04$} & \multicolumn{2}{|c|}{$0.66 \pm 0.09$} & \multicolumn{2}{|c|}{$0.69 \pm 0.22$} \\
\hline
\end{tabular}

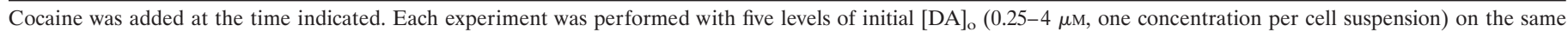

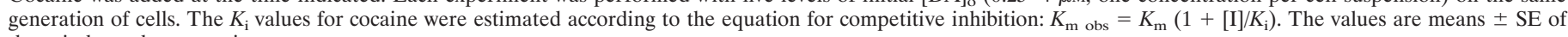
three independent experiments.

${ }^{*} p<0.01$ vs [ouabain] $=0$ (Newman-Keuls test).

$* * p<0.01$ vs [cocaine] $=0$ (Newman-Keuls test).

Table 2. Effect of equilibrated cocaine on the initial rate of DA uptake in the LLC-hNET cells preloaded with or without $m$-tyramine

\begin{tabular}{llll} 
& \multicolumn{2}{l}{$\begin{array}{l}\text { Initial rate of DA uptake } \\
(\mathrm{pmol} / \mathrm{sec} / \mathrm{mg})\end{array}$} & \\
\cline { 2 - 3 } & Control & Cocaine $1 \mu \mathrm{M}$ & Inhibition $(\%)$ \\
\hline$-m$-Tyramine & $7.92 \pm 0.13$ & $5.34 \pm 0.10$ & $32.3 \pm 1.4$ \\
$+m$-Tyramine & $7.58 \pm 0.12$ & $5.12 \pm 0.16$ & $32.6 \pm 2.2$
\end{tabular}

Cells were preincubated with or without $3 \mu \mathrm{M} m$-tyramine at $37^{\circ} \mathrm{C}$ for $8 \mathrm{~min}$. The treated cells were washed with KRH buffer once and then used for uptake assays. Cocaine was added 6 min before the initiation of the DA $(1 \mu \mathrm{M})$ uptake. The values are means $\pm \mathrm{SE}$ of seven experiments.

\section{Cocaine added 6 min earlier than $D A$}

To explore the inhibition pattern of equilibrated cocaine, a 6 min preincubation of cells with cocaine was performed. Within this preincubation period, cocaine was expected to reach its binding plateau (Calligaro and Eldefrawi, 1987) and to distribute across the membrane with intracellular cocaine concentration higher than extracellular cocaine concentration (Sershen et al., 1982; Sulzer and Rayport, 1990).

Preincubation of the cells with $2 \mu \mathrm{M}$ cocaine also inhibited DA uptake in a competitive manner (Fig. $3 B$ ). Its $K_{\mathrm{i}}$ was slightly lower than that obtained with concurrent addition of cocaine and DA (Table 1) but did not reach statistical significance. To inspect the impact of the intracellular $\left[\mathrm{Na}^{+}\right]$on the inhibition pattern of cocaine, we examined the effect of cocaine on DA uptake at higher intracellular $\left[\mathrm{Na}^{+}\right]$by partially inhibiting the $\mathrm{Na}^{+}, \mathrm{K}^{+}$ATPase with ouabain. The presence of ouabain $(200 \mu \mathrm{M})$ in the medium strongly reduced DA uptake in a mixed competitive and noncompetitive manner, with $K_{\mathrm{m}}$ increasing and $V_{\max }$ decreasing (Table 1). However, ouabain failed to change the inhibition pattern of cocaine (Fig. $3 C$ ). Under this condition, cocaine still affected DA uptake by elevating the $K_{\mathrm{m}}$ without effect on $V_{\max }$ (Table 1). The $K_{\mathrm{i}}$ of cocaine in the presence of ouabain was similar to its $K_{\mathrm{i}}$ in the absence of ouabain (Table 1 ).

To investigate the contribution of internal substrates to the inhibitory effect of equilibrated cocaine on DA uptake, we tested the initial rates of DA uptake in cells containing no $m$-tyramine or in cells preloaded with $m$-tyramine $(3 \mu \mathrm{M})$ in the absence and presence of $1 \mu \mathrm{M}$ cocaine. Preloading of cells with $m$-tyramine did not significantly reduce the initial rate of DA uptake (Table 2). Moreover, equilibrated cocaine showed identical effects on the
DA uptake into cells preloaded without and with $m$-tyramine (Table 2).

\section{Effect of cocaine on outward transport of dopamine} $D A$ efflux at various $[D A]_{i}$ and a fixed initial [m-tyramine] With the initial $[m \text {-tyramine }]_{\mathrm{o}}$ fixed at $10 \mu \mathrm{M}$, initial rates of internal DA transport out of the cells were determined at various concentrations of intracellular DA and initial medium cocaine. The typical time course is shown in Figure 4. Cocaine reduced the initial efflux rate at all tested preloading concentrations of DA (Fig. 4, compare $A, B$ ). The DA efflux in the presence of cocaine alone (Fig. $4 C$ ) results from diffusion of internal DA that is normally offset by uptake (Chen et al., 1998). Inhibition of hNET by cocaine made this efflux visible. At higher preloading [DA], this nonspecific efflux rate constituted an appreciable part of DA efflux rate observed in the presence of both $m$-tyramine and cocaine (Fig. 4, compare $B, C$ ). The regression equations expressing the relationship between cocaine-induced apparent DA efflux and initial $[\mathrm{DA}]_{\mathrm{o}}(0.5-4 \mu \mathrm{M})$ were: initial rate (picomoles per second per milligram $)=0.001+0.178[\mathrm{DA}]_{\mathrm{o}}$ at $3 \mu \mathrm{M}$ [cocaine] $(r=0.999 ; n=3), 0.022+0.24[\mathrm{DA}]_{\mathrm{o}}$ at $10 \mu \mathrm{M}$ [cocaine] $(r=$ $0.997 ; n=3)$, and $-0.02+0.349[\mathrm{DA}]_{\mathrm{o}}$ at $30 \mu \mathrm{M}$ [cocaine] $(r=$ $0.999 ; n=3)$, respectively. The initial rate of cocaine-induced apparent DA efflux at each initial $[\mathrm{DA}]_{\mathrm{o}}$ was calculated from the equation and subtracted from the initial rate of the DA efflux in the presence of both $m$-tyramine and cocaine.

The design of the experiment allowed assessment of the inhibition pattern of cocaine in two ways. First, the $\mathrm{IC}_{50}$ values of cocaine to inhibit $m$-tyramine-induced DA efflux were estimated at several fixed $[\mathrm{DA}]_{\mathrm{i}}$ (Table 3$)$. An increment in $[\mathrm{DA}]_{\mathrm{i}}$ did not significantly change the $\mathrm{IC}_{50}$ value of cocaine (Table 3 ). It can be seen that the steady state [DA] ofore initiation of the DA efflux was $<400 \mathrm{~nm}$ (Table 3 ), which was too low to significantly affect the effect of $m$-tyramine $(10 \mu \mathrm{M})$ or cocaine $(3-30 \mu \mathrm{M})$. Second, the kinetic parameters for the DA efflux were estimated at several fixed [cocaine]. An increase in [cocaine] reduced $V_{\max }$ without significantly changing $K_{\mathrm{m}}$ (Table 4 ). Both results indicated noncompetitive inhibition of DA efflux by cocaine. In addition, a similar conclusion can be obtained from the Eadie-Hofstee transformation of the efflux data (Fig. 5A).

$D A$ efflux at various initial [m-tyramine $]_{o}$ and a fixed $[D A]_{i}$ With $[D A]_{i}$ fixed at $84 \mu \mathrm{M}$, the initial efflux rates were determined at various initial medium concentrations of $m$-tyramine and co- 


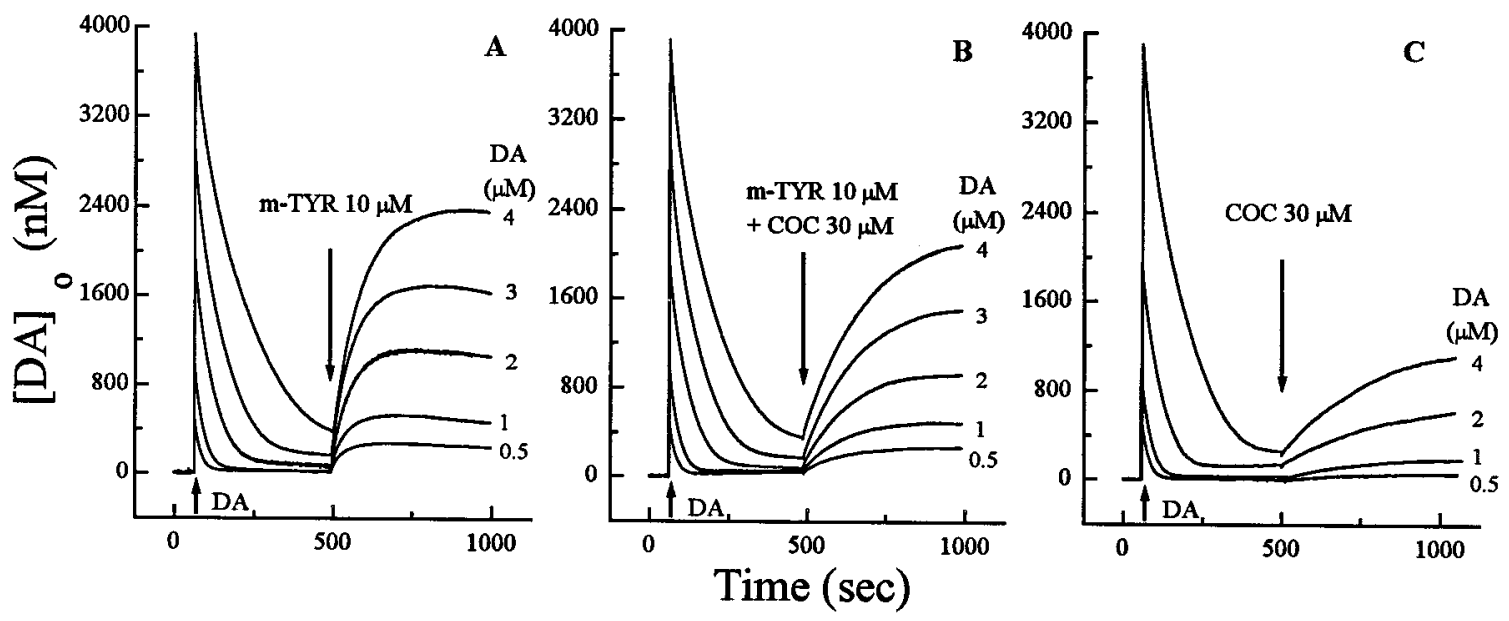

Figure 4. Time course of $m$-tyramine ( $m$-TYR)-induced DA efflux at various intracellular concentrations of DA. DA was added to an initial medium concentration of $0.5-4 \mu \mathrm{M}$ and allowed to be taken up until [DA $]_{\mathrm{o}}$ decreased to near steady state, at which time, the intracellular DA concentrations ranged from 44 to $321 \mu \mathrm{M}$. The DA efflux was subsequently initiated by $10 \mu \mathrm{M} \mathrm{m}$-tyramine in the absence and presence of $30 \mu \mathrm{M}$ cocaine $(C O C)$. Each panel shows a representative experiment with indicated levels of initial [DA $]_{\mathrm{o}}$ on the same generation of cells. Each experiment was performed three times with similar results. The arrow denotes the addition time of DA, $m$-tyramine, cocaine, or $m$-tyramine plus cocaine. The values at the end of each curve denote the initial medium DA concentration. $A$, DA efflux in the presence of $m$-tyramine alone. $B$, DA efflux in the presence of both $m$-tyramine and cocaine. Cocaine reduced the initial rate of the DA efflux, although cocaine itself caused an apparent DA efflux $(C)$. This experiment was run in parallel with the experiment in $A$. $C$, DA efflux in the presence of cocaine alone. The initial rate of the DA efflux in the presence of cocaine was slower but proportional to the initial $[\mathrm{DA}]_{\mathrm{o}}$ in a linear manner. The initial rate of DA efflux in the presence of $30 \mu \mathrm{M}$ cocaine alone at $3 \mu \mathrm{M}$ initial $[\mathrm{DA}]_{\mathrm{o}}$ was not measured in this particular experiment, but it can be estimated from the linear regression equation obtained from this experiment (see Results). In other experiments, measurement of the apparent DA efflux induced by cocaine at $3 \mu \mathrm{M}$ initial [DA] gave values similar to those estimated from the regression equation. For estimation of the initial rate of $m$-tyramine-induced DA efflux in the presence of cocaine, the subtraction was made at each initial $[\mathrm{DA}]_{\mathrm{o}}$ as follows: Rate $_{\mathrm{TYR}, \mathrm{COC}}=$ Rate $_{\mathrm{TYR}+\mathrm{COC}}-$ Rate $_{\mathrm{COC}}$.

Table 3. Inhibition by cocaine of m-tyramine-induced DA efflux as a function of DA concentrations
\begin{tabular}{lllll} 
& & & \\
Initial $[\mathrm{DA}]_{\mathrm{o}}(\mu \mathrm{M})$ & $\begin{array}{l}{[\mathrm{DA}]_{\mathrm{o}} \text { at steady }} \\
\text { state }(\mathrm{nM})\end{array}$ & $\begin{array}{l}{[\mathrm{DA}]_{\mathrm{i}} \text { at steady }} \\
\text { state }(\mu \mathrm{M})\end{array}$ & $\mathrm{IC}_{50}(\mu \mathrm{M})^{a}$ & $K_{\mathrm{i}}(\mu \mathrm{M})^{a}$ \\
\hline & $n=12$ & $n=4$ & $n=3$ & $n=3$ \\
0.5 & $23 \pm 4$ & 44 & $11.6 \pm 0.6$ & $2.05 \pm 0.07$ \\
1.0 & $27 \pm 5$ & 84 & $12.2 \pm 0.6$ & $2.23 \pm 0.16$ \\
1.5 & $44 \pm 3$ & 124 & $12.9 \pm 1.3$ & $2.17 \pm 0.04$ \\
2.0 & $88 \pm 8$ & 163 & $12.4 \pm 0.8$ & $2.15 \pm 0.11$ \\
3.0 & $184 \pm 15$ & 242 & $11.0 \pm 1.2$ & $2.22 \pm 0.12$ \\
4.0 & $359 \pm 38$ & 321 & $13.4 \pm 1.5$ & $2.47 \pm 0.24$
\end{tabular}

$m$-Tyramine $(10 \mu \mathrm{M})$ and cocaine $(0-30 \mu \mathrm{M})$ were added at the same time. The data at $0.5,1,2,3$, and $4 \mu \mathrm{M}$ initial [DA] were obtained from the same experiments as in Fig. 5 . The data at $1.5 \mu \mathrm{M}$ initial [DA $]_{\mathrm{o}}$ were obtained from other experiments. $\mathrm{IC}_{50}$ was computed by nonlinear fitting the efflux data with logistic equation. All Hill numbers were close to unity (data not shown). For $K_{\mathrm{i}}$, data were analyzed by the least square linear regression of the $\mathrm{v} / \mathrm{v}^{\prime}$ as a function of the concentrations of an inhibitor. $K_{\mathrm{i}}$ was estimated according to the equation: $K_{\mathrm{i}}=1 /$ s slope of the regression line $\left.x\left(1+[S] / K_{\mathrm{s}}\right)\right\}$. [S] is the $m$-tyramine concentration. $K_{\mathrm{s}}$ is the Michaelis-Menten constant for $m$-tyramine to induce DA efflux, and was set at $2.02 \mu \mathrm{M}$, which was the average value determined in separate saturation curves (see Table 4). [DA] at steady state was measured by RDE voltammetry. [DA $]_{i}$ was estimated from the linear regression equation expressing the relationship between initial $[\mathrm{DA}]_{\mathrm{o}}$ and $[\mathrm{DA}]_{\mathrm{i}}$ (see Fig. 1). The values are means \pm SE of $n$ experiments.

${ }^{a}$ No significant difference for any [DA] (Newman-Keuls test).

caine. The typical time course was shown in Figure 6. High concentrations ( 30 and $100 \mu \mathrm{M}$ ) of $m$-tyramine released $\sim 70 \%$ of DA taken up by the cells (Fig. $6 \mathrm{~A}$ ), which was compatible with the DA recovery ( $\sim 64 \%$ of added DA) from the cells determined by HPLC at 5-10 min after the addition of DA. This suggests that almost all intracellular DA could be released by high concentrations of $m$-tyramine. Cocaine reduced the initial efflux rate more appreciably at lower initial [ $m$-tyramine] than at higher initial [ $m$-tyramine $]_{\mathrm{o}}$ (Fig. $6 \mathrm{~B}$ ). The slow rise in the early phase of the apparent DA efflux caused by cocaine alone stood in sharp contrast to the steep rising in the early phase of the DA efflux induced by the same concentrations of $m$-tyramine (Fig. 6, com- pare $A, C)$. The Michaelis-Menten equation expressing the relationship between initial rate of cocaine-induced apparent DA efflux and initial medium [cocaine] was: initial rate (picomoles per second per milligram $)=0.26[$ cocaine $] /(3.0+$ [cocaine $])$ with a Hill number $1.02 \pm 0.025(n=6)$. Thus, the maximal initial rate of cocaine-induced DA efflux was only $3 \%$ of that induced by $m$-tyramine $\left(0.26 \mathrm{vs} 7.7 \mathrm{pmol} \cdot \mathrm{sec}^{-1} \cdot \mathrm{mg}^{-1}\right)$ at $84 \mu \mathrm{M}[\mathrm{DA}]_{\mathrm{i}}$, suggesting that the contribution of inhibiting reuptake of external DA by $m$-tyramine to the observed DA efflux is negligible.

The Eadie-Hofstee plot of the data showed that the inhibition pattern produced by cocaine was competitive (Fig. $5 B$ ); $V_{\max }$ is unchanged and $K_{\mathrm{m}}$ increased with medium [cocaine] (Table 4). 


\begin{tabular}{|c|c|c|c|c|c|}
\hline \multicolumn{3}{|l|}{ Dopamine } & \multicolumn{3}{|c|}{$m$-Tyramine } \\
\hline $\begin{array}{l}\text { [Cocaine] } \\
(\mu \mathrm{M})\end{array}$ & $K_{\mathrm{m} \text { obs }}(\mu \mathrm{M})$ & $\begin{array}{l}V_{\max \text { obs }} \\
(\mathrm{pmol} / \mathrm{sec} / \mathrm{mg})\end{array}$ & $\begin{array}{l}\text { [Cocaine] } \\
(\mu \mathrm{M})\end{array}$ & $K_{\mathrm{m} \text { obs }}(\mu \mathrm{M})$ & $\begin{array}{l}V_{\text {max obs }} \\
(\mathrm{pmol} / \mathrm{sec} / \mathrm{mg})\end{array}$ \\
\hline 0 & $364 \pm 31$ & $23 \pm 3$ & 0 & $2.0 \pm 0.5$ & $7.8 \pm 0.8$ \\
\hline 3 & $356 \pm 47$ & $18 \pm 3$ & 3 & $4.8 \pm 0.9^{*}$ & $7.4 \pm 0.8$ \\
\hline 10 & $378 \pm 35$ & $13 \pm 1^{* *}$ & 6 & $6.7 \pm 0.7^{* *}$ & $7.0 \pm 0.8$ \\
\hline 30 & $401 \pm 81$ & $8 \pm 2 * *$ & 10 & $10.6 \pm 1.2^{* *}$ & $7.2 \pm 1.0$ \\
\hline
\end{tabular}

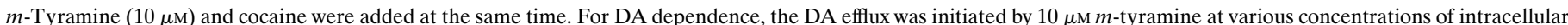

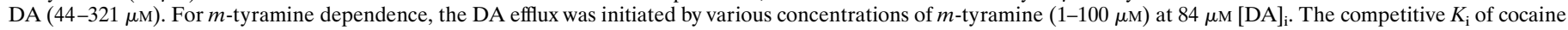
in the latter experiment was $2.36 \pm 0.43 \mu \mathrm{M}$, estimated as described in Table 1 . The values are means \pm SE of three independent experiments.

$* p<0.05$.

$* * p<0.01$ vs [cocaine] $=0$ (Newman-Keuls test $)$.

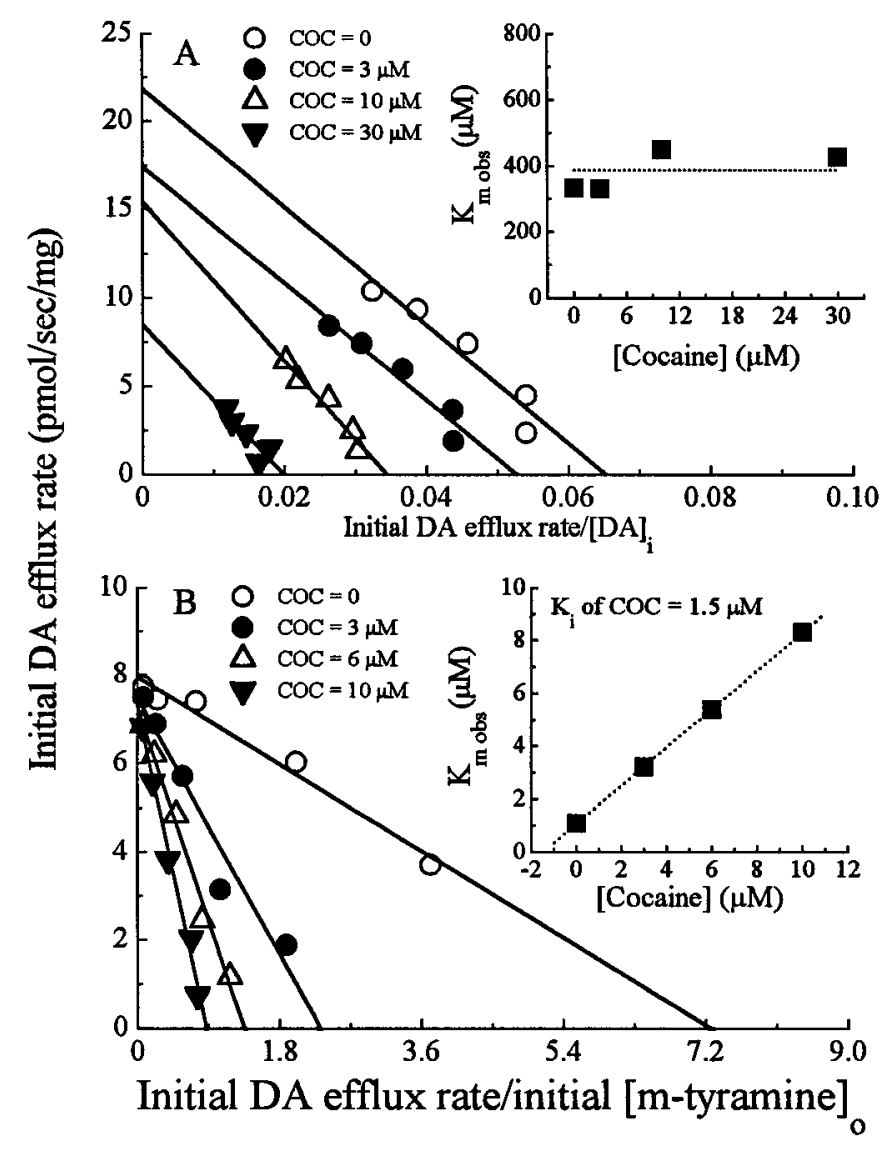

Figure 5. Inhibitory patterns of cocaine $(C O C)$ on $m$-tyramine-induced DA efflux. Eadie-Hofstee plots were used to analyze the inhibition patterns. The straight solid line represents the result of the least squares linear regression. Each panel shows a representative experiment with five levels of [substrate] on the same generation of cells. Each experiment was performed three times with similar results. $A$, Noncompetitive inhibition pattern of cocaine relative to $[\mathrm{DA}]_{\mathrm{i}}(44-321 \mu \mathrm{M})$. The protocol applied is depicted in Figure 4. Inset shows replot of $K_{\mathrm{m}}$ obs obtained from the Eadie-Hofstee plot as a function of cocaine concentration. The straight dotted line represents the average value of $K_{\mathrm{m}}$ obs obtained from this experiment. $B$, Competitive inhibition pattern of cocaine relative to initial [m-tyramine $]_{\mathrm{o}}(1-100 \mu \mathrm{M})$. The protocol applied is depicted in Figure 6. Inset shows replot of $K_{\mathrm{m} \text { obs }}$ obtained from the Eadie-Hofstee plot as a function of the concentration of cocaine. The straight dotted line represents the predicted shift in $K_{\mathrm{m} \text { obs }}$ by the competitive model.
The graphically estimated competitive $K_{\mathrm{i}}$ for cocaine was $2.36 \pm$ $0.43 \mu \mathrm{M}$. Based on the competitive model, $K_{\mathrm{i}}$ values for cocaine to inhibit $m$-tyramine $(10 \mu \mathrm{M})$-induced DA efflux at various [DA] were estimated. The $K_{\mathrm{i}}$ values at all levels of [DA $]_{\mathrm{i}}$ were similar and close to the graphically estimated $K_{\mathrm{i}}$ (Table 4). However, these $K_{\mathrm{i}}$ values for cocaine to inhibit $m$-tyramine-induced DA efflux were significantly higher than its $K_{\mathrm{i}}$ to inhibit DA uptake (Table $1 ; p<0.01$; unpaired $t$ test).

\section{Concurrent effect of cocaine on inward transport of $\boldsymbol{m}$-tyramine and outward transport of dopamine}

To clarify which conformation of the hNET cocaine attacks, we used a two-electrode approach to examine the simultaneous uptake of $m$-tyramine and the efflux of DA induced by $m$-tyramine in a single run. The typical time course for the original signals and the normalized concentration profiles in the absence and presence of cocaine are shown in Figure 7.

\section{m-Tyramine uptake and accompanying $D A$ efflux in the absence of cocaine}

Change in the $[\mathrm{DA}]_{\mathrm{i}}$ (Fig. $8 A$ ) did not modify the initial rate of $m$-tyramine uptake, reminiscent of the insensitivity of DA uptake to the intracellular $m$-tyramine (Table 2 ). The slightly lower rate value at highest $[\mathrm{DA}]_{\mathrm{i}}$ did not reach significance when compared with that at lowest $[\mathrm{DA}]_{\mathrm{i}}\left(12.8 \pm 0.8 \mathrm{pmol} \cdot \mathrm{sec}^{-1} \cdot \mathrm{mg}^{-1}\right.$ at 14.9 $\mu \mathrm{M}[\mathrm{DA}]_{\mathrm{i}}$ vs $11.9 \pm 0.9 \mathrm{pmol} \cdot \mathrm{sec}^{-1} \cdot \mathrm{mg}^{-1}$ at $242 \mu \mathrm{M}[\mathrm{DA}]_{\mathrm{i}} ; p>$ $0.05 ; n=6$; paired $t$ test). In contrast, $m$-tyramine-induced DA efflux significantly increased with $[\mathrm{DA}]_{\mathrm{i}}$ (Fig. $\left.8 \mathrm{~B}\right)$. The ratios of DA efflux to $m$-tyramine uptake were $<1$ at all tested [DA] . However, the ratio increased with $[\mathrm{DA}]_{\mathrm{i}}$ and followed the relationship defined by Michaelis-Menten kinetic models (Fig. 9), with $R_{\max }=1.01 \pm 0.10$ and $K_{0.5}=340 \pm 48 \mu \mathrm{M}$. Thus, theoretically, with the intracellular DA approaching infinitely high concentration, the efflux rate of internal DA would equal the uptake rate of external $m$-tyramine.

\section{Cocaine added simultaneously with m-tyramine}

This was examined because the noncompetitive pattern of cocaine on the DA efflux was found with respect to $[\mathrm{DA}]_{\mathrm{i}}$ when cocaine and $m$-tyramine were added at the same time. Cocaine (3 $\mu \mathrm{M})$, added simultaneously with $m$-tyramine, significantly reduced both $m$-tyramine uptake and accompanying DA efflux. In agreement with the results obtained from one-electrode measurement of DA uptake and efflux, DA preloading did not significantly modify the inhibitory effect of cocaine either on the $m$-tyramine uptake or on the accompanying DA efflux (Fig. 8).

By using the Michaelis-Menten expression of the DA efflux 

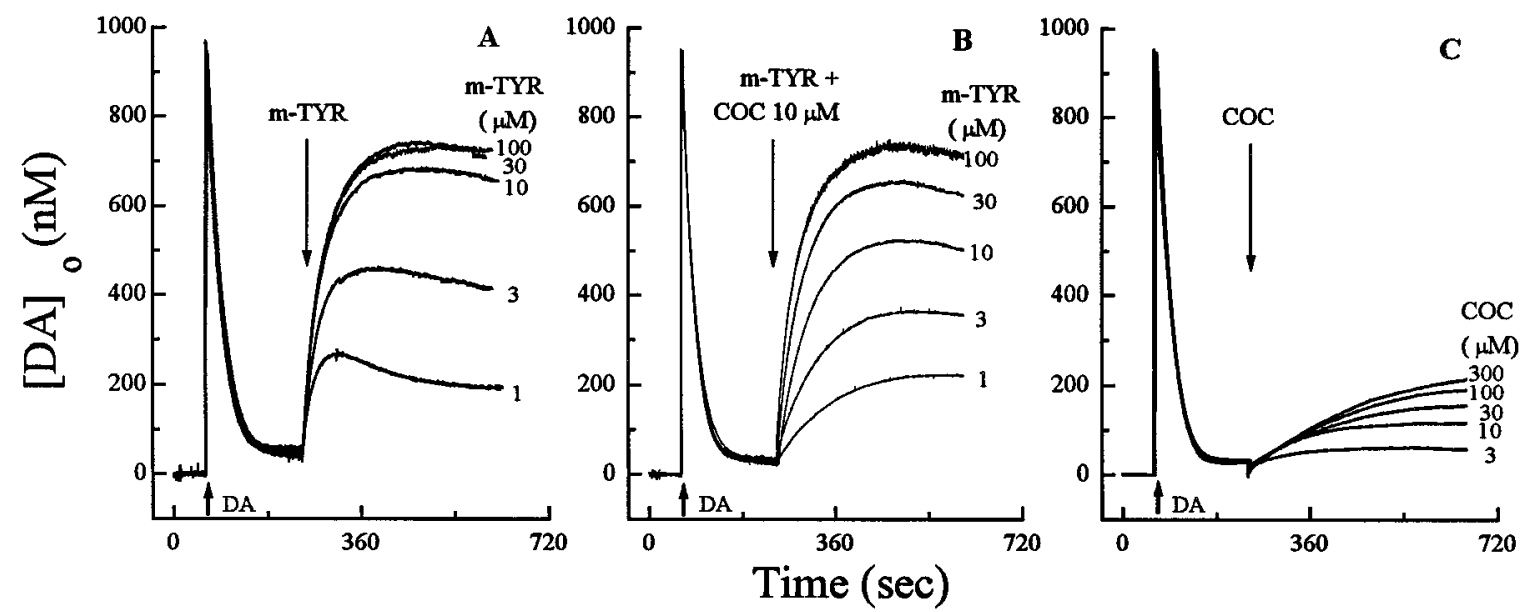

Figure 6. Time course of DA efflux induced by various concentrations of $m$-tyramine $(m-T Y R)$ at a fixed intracellular concentration of DA. DA was added to an initial medium concentration of $1 \mu \mathrm{M}$ and allowed to be taken up until [DA $]_{\mathrm{o}}$ decreased to near steady state, at which time, [DA $]_{\mathrm{i}}$ was 84 $\mu \mathrm{M}$. The DA efflux was subsequently initiated by various concentrations of $m$-tyramine $(1-100 \mu \mathrm{M})$ in the absence and presence of $10 \mu \mathrm{M}$ cocaine. Each panel shows a representative experiment with five levels of initial [ $m$-tyramine $]_{o}$ or [cocaine] on the same generation of cells. Each experiment was performed three times with similar results. The arrow denotes the addition time of DA, $m$-tyramine, cocaine, or $m$-tyramine plus cocaine. The values at the end of each curve denote the initial medium $m$-tyramine concentration. $A$, DA efflux in the presence of $m$-tyramine alone. $B$, DA efflux in the presence of both $m$-tyramine and cocaine. Cocaine reduced the initial rate of the DA efflux more appreciably at lower $[m \text {-tyramine }]_{0}$ than at higher $[m \text {-tyramine }]_{\mathrm{o}} . C$, DA efflux in the presence of cocaine alone. For estimation of the initial rate of $m$-tyramine-induced DA efflux in the presence of cocaine, the subtraction was made at each [cocaine] as follows: Rate $_{\mathrm{TYR}, \mathrm{COC}}=$ Rate $_{\mathrm{TYR}+\mathrm{COC}}-$ Rate $_{\mathrm{COC}}$.

Figure 7. Simultaneous measurement of $m$-tyramine $(m-T Y R)$ uptake and accompanying DA efflux by two-electrode RDE voltammetry. DA was added to an initial medium concentration of 1 $\mu \mathrm{M}$ and allowed to be taken up until $[\mathrm{DA}]_{\mathrm{o}}$ decreased to near steady state, at which time, $[\mathrm{DA}]_{\mathrm{i}}$ was $84 \mu \mathrm{M}$. DA efflux was initiated by $3 \mu \mathrm{M}$ $m$-tyramine in the absence and presence of $3 \mu \mathrm{M}$ cocaine $(C O C)$. Data shown are from a representative experiment on the same generation of cells. Each experiment was performed six times with similar results. The arrow denotes the addition time of DA, $m$-tyramine, or $m$-tyramine plus cocaine. $A$, Oxidation signals measured in the absence of cocaine. Electrode 1 recorded the DA signal while electrode 2 recorded both DA and $m$-tyramine signals. $B$, Oxidation signals measured in the presence of $3 \mu \mathrm{M}$ cocaine. $C$, Concurrent changes in medium DA and $m$-tyramine signals in the absence of cocaine, determined by subtraction of the DA signal at electrode 1 from the mixed signal at electrode 2 plotted in $A$ after correction for relative response. $D$, Concurrent changes in medium DA and $m$-tyramine signals in the presence of $3 \mu \mathrm{M}$ cocaine, determined as in $C$. For estimation of the initial rate of $m$-tyramine uptake in the absence and presence of $3 \mu \mathrm{M}$ cocaine, the subtraction was made as follows: $m$-tyramine uptake rate $=$ total decay rate - decay rate with 100 accompanying DA efflux are reduced by cocaine.
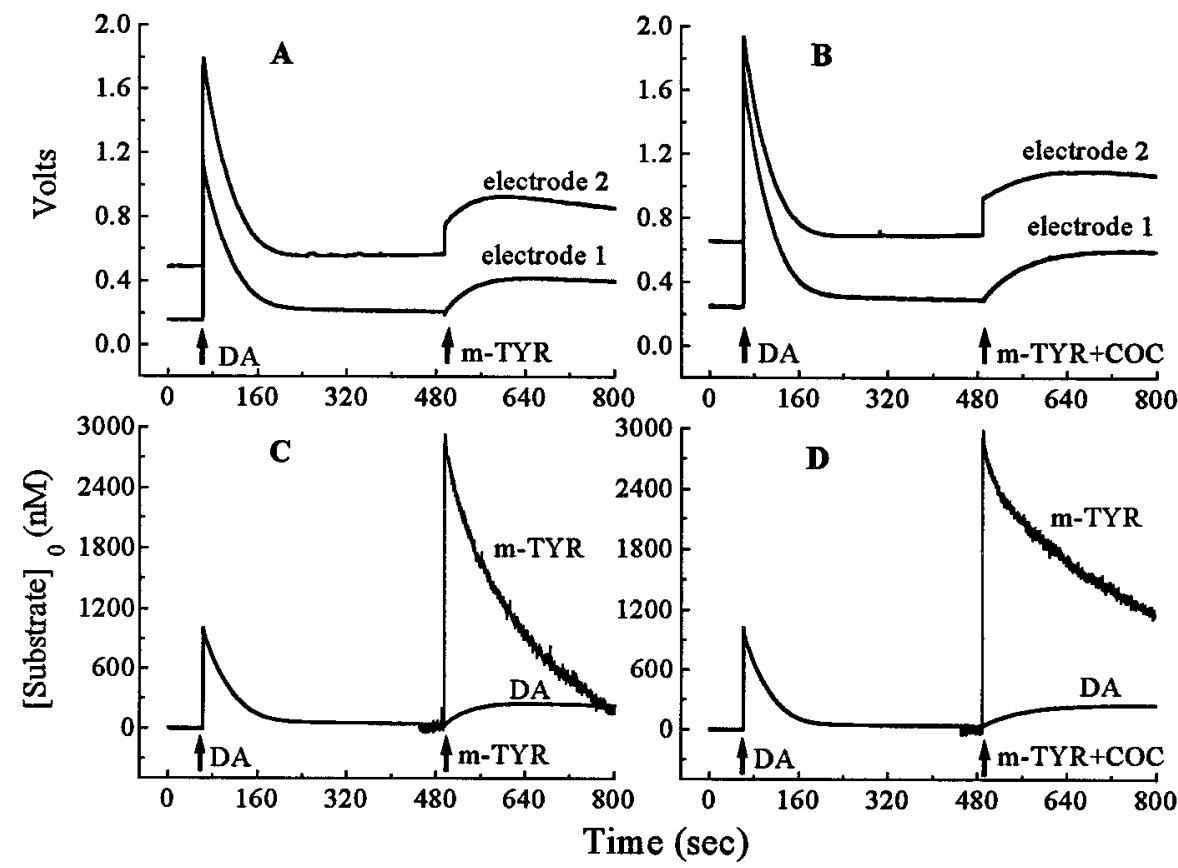

$\mu \mathrm{M}$ cocaine (data not shown). Comparison of $C$ with $D$ reveals that both $m$-tyramine uptake and modified for the inhibition mechanisms under consideration, we compared the experimental ratio curve with those predicted from the models. The reasoning is as follows. Cocaine could inhibit $m$-tyramine-induced DA efflux by two ways: (1) competing with $m$-tyramine for the outward-facing hNET, thereby reducing the amount of the inward-facing hNET available for internal DA; and (2) directly interacting with internal DA at the inward-facing hNET. If cocaine does not interact with the inward-facing hNET, the reduction in DA efflux in the presence of cocaine would be solely caused by the reduction in $m$-tyramine uptake. In this case, the ratio of DA efflux to $m$-tyramine uptake at any $[\mathrm{DA}]_{\mathrm{i}}$ will be the same as that in the absence of cocaine. If cocaine has an additional effect on the inward-facing hNET, it would cause further reduction in DA efflux, that is, the DA efflux would decrease more than predicted from the reduction in $m$-tyramine uptake, resulting in a lower ratio. In this case, the ratio curve in the presence of cocaine would shift to the right relative to that in the absence of cocaine, with its shape varying with the putative inhibition patterns of cocaine at the inward-facing hNET (Fig. 9). Thus, the shift would be more significant at lower $[\mathrm{DA}]_{\mathrm{i}}$ for a 

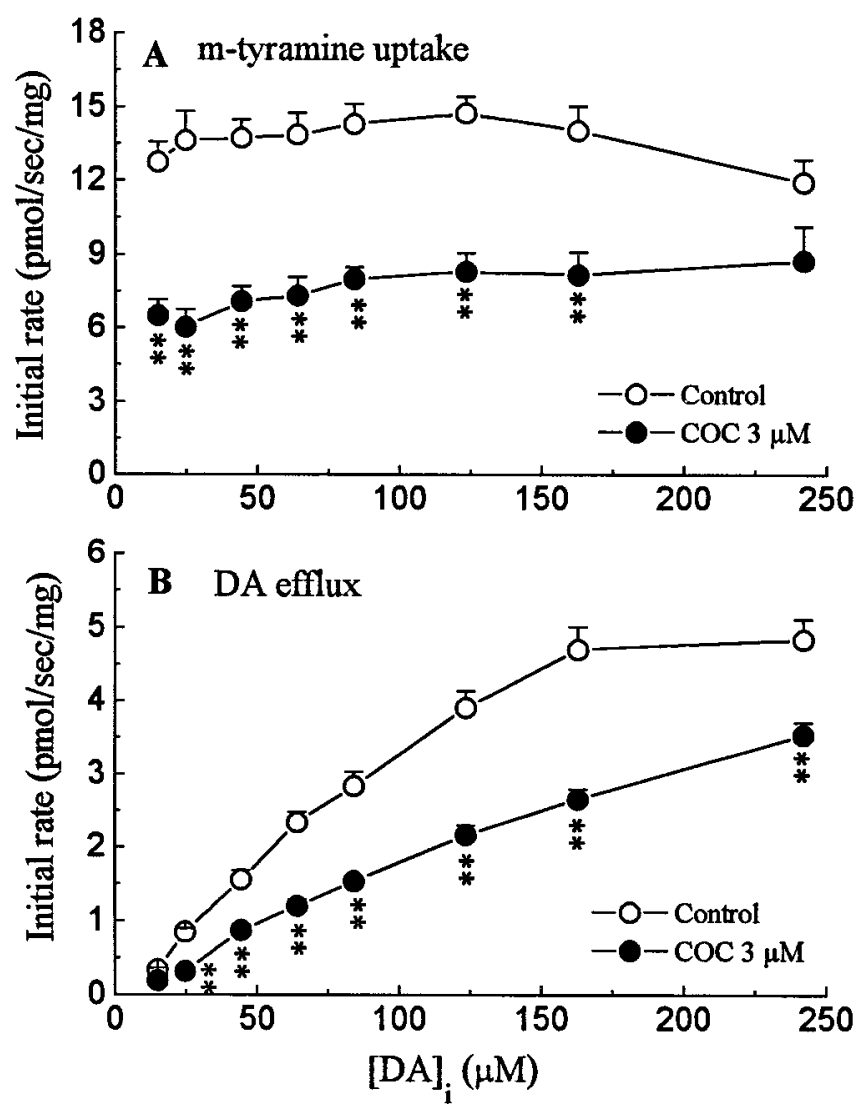

Figure 8 . Inhibition by cocaine of $m$-tyramine uptake and $m$-tyramineinduced DA efflux at various intracellular concentrations of DA. The initial medium concentration of $m$-tyramine was $3 \mu \mathrm{M}$. The protocol applied is depicted in Figure 7. $A$, Inhibition of $m$-tyramine uptake. Intracellular DA has no significant effect on $m$-tyramine uptake or on the inhibitory effect of cocaine. $B$, Inhibition of $m$-tyramine-induced DA efflux. The DA efflux increases with $[\mathrm{DA}]_{\mathrm{i}}$ but is almost equally inhibited by cocaine at most $[\mathrm{DA}]_{\mathrm{i}}(59,38,56,51,54,55,56$, and $73 \%$ of control at $14.9,24.8,44.5,64.2,84,123.5,163$, and $242 \mu \mathrm{M}[\mathrm{DA}]_{\mathrm{i}}$, respectively). Values are mean \pm SE of six experiments, each of which was performed with eight concentrations of DA on the same generation of cells. ${ }^{* *} p<$ 0.01 versus control.

competitive inhibition, more significant at higher $[\mathrm{DA}]_{\mathrm{i}}$ for an uncompetitive inhibition, and equal (in terms of percent inhibition) at all $[\mathrm{DA}]_{\mathrm{i}}$ for a noncompetitive inhibition.

When added simultaneously with $m$-tyramine, cocaine did not change the $m$-tyramine uptake to DA efflux ratio at all tested $[D A]_{i}$ (Fig. 9). For the ratio curve in the presence of cocaine, the $R_{\max }$ was $0.95 \pm 0.10$, and the $K_{0.5}$ was $319 \pm 48 \mu \mathrm{M}$, which were close to the values in the absence of cocaine. All models for an inhibition at the inward-facing conformation needed a $K_{\mathrm{i}}$ value of $100 \mu \mathrm{M}$ to obtain a ratio curve close to that without cocaine.

\section{Cocaine added 6 min earlier than m-tyramine}

This experiment was designed to test whether cocaine could affect $m$-tyramine-induced DA efflux by interacting with internal DA if it was allowed to equilibrate with the transporters or to fully enter the cell. Cocaine was added to various medium concentrations at a time point when the DA $(1 \mu \mathrm{M})$ uptake reached equilibrium (4 min after DA addition), and incubated with the DA-preloaded cells for 6 min before the addition of $m$-tyramine $(3 \mu \mathrm{M})$. Under this condition, after initiation of the DA efflux by

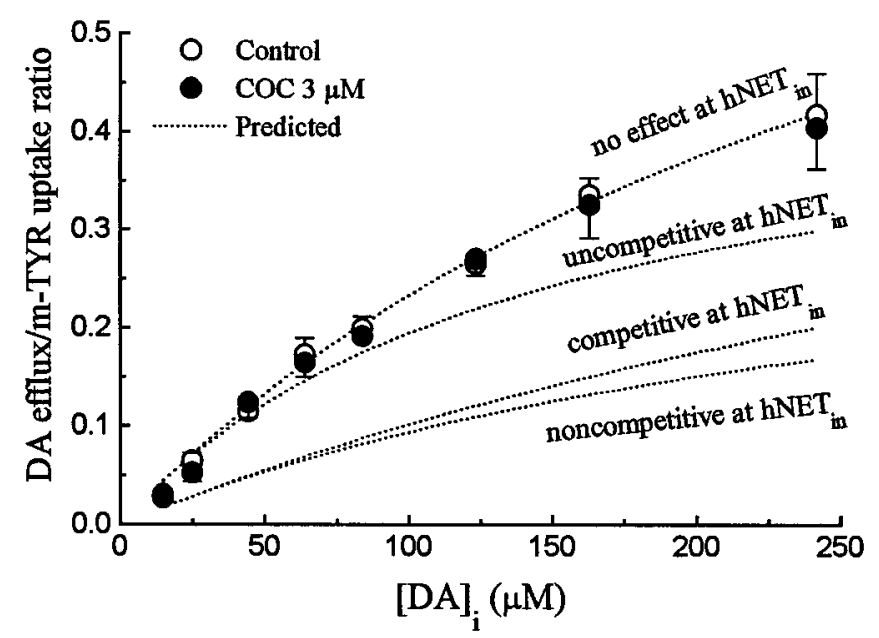

Figure 9. The ratio of DA efflux to $m$-tyramine uptake at various intracellular concentrations of DA. Cocaine did not shift the ratio curve. The dotted lines represent predicted shifts of the ratio curve in the presence of $3 \mu \mathrm{M}$ cocaine, based on no interaction, competitive interaction, noncompetitive interaction, or uncompetitive interaction of cocaine with intracellular DA at the inward-facing conformation of the hNET ( $\left.\mathrm{hNET}_{\text {in }}\right)$. The predicted ratio of DA efflux to $m$-tyramine uptake for each model was estimated as described in Materials and Methods.

Table 5. Equal inhibition by equilibrated cocaine of $m$-tyramine uptake and $m$-tyramine-induced DA efflux

[Cocaine] $m$-Tyramine uptake DA efflux

\begin{tabular}{rcll}
$(\mu \mathrm{M})$ & $(\mathrm{pmol} / \mathrm{sec} / \mathrm{mg})$ & $(\mathrm{pmol} / \mathrm{sec} / \mathrm{mg})$ & Efflux/uptake Ratio \\
\hline 0 & $10.7 \pm 0.3$ & $1.66 \pm 0.08$ & $0.16 \pm 0.01$ \\
1 & $8.7 \pm 0.6$ & $1.43 \pm 0.08$ & $0.16 \pm 0.01$ \\
3 & $6.8 \pm 0.6$ & $1.08 \pm 0.03$ & $0.16 \pm 0.02$ \\
10 & $4.4 \pm 0.6$ & $0.62 \pm 0.04$ & $0.15 \pm 0.02$ \\
$\mathrm{IC}_{50}$ & $6.25 \pm 0.28$ & $5.93 \pm 0.38$ & \\
$\mathrm{H}_{\mathrm{i}}$ & $0.83 \pm 0.04$ & $1.00 \pm 0.05$ & \\
\hline
\end{tabular}

Cells were preloaded with $84 \mu \mathrm{M}$ DA. Cocaine was added to the medium for $6 \mathrm{~min}$ followed by an addition of $m$-tyramine $(3 \mu \mathrm{M}) . \mathrm{IC}_{50}$ values and Hill numbers were computed by nonlinear fitting the data with logistic equation. The competitive $K_{\mathrm{i}}$ for cocaine to inhibit $m$-tyramine-induced DA efflux (see Table 3 for method) was $2.57 \pm 0.36 \mu \mathrm{M}$. The values are means $\pm \mathrm{SE}$ of four experiments.

$m$-tyramine, the intracellular [cocaine] could be between 1 and 25 $\mu \mathrm{M}$ (assuming 2.5-fold concentrated in the cell; Sulzer and Rayport, 1990), or between 4 and $40 \mu \mathrm{M}$ (assuming fourfold concentrated in the cell; Sershen et al., 1982). Despite this possible intracellular accumulation of cocaine, the DA efflux/ $m$-tyramine uptake ratio remained unchanged (Table 5). In addition, the $\mathrm{IC}_{50}$ of cocaine for inhibiting $m$-tyramine uptake was similar to its $\mathrm{IC}_{50}$ for inhibiting accompanying DA efflux (Table 5).

The competitive $K_{\mathrm{i}}$ of cocaine for inhibiting $m$-tyramine (3 $\mu \mathrm{M}$ )-induced DA efflux was $2.57 \pm 0.36 \mu \mathrm{M}$. This value was close to its $K_{\mathrm{i}}$ for inhibiting $m$-tyramine $(10 \mu \mathrm{M})$-induced DA efflux when cocaine was added simultaneously with $m$-tyramine (2-2.5 $\mu \mathrm{M}$, Table 3 ). The $K_{\mathrm{i}}$ of cocaine for inhibiting $m$-tyramine was not available because of the lack of information about the $K_{\mathrm{m}}$ of $m$-tyramine uptake. The filming at the electrode surface by $m$ tyramine varies in degree with the concentration of $m$-tyramine, which hampered our attempts to measure the $K_{\mathrm{m}}$ of $m$-tyramine uptake into DA-preloaded cells under the present electrochemical conditions. 


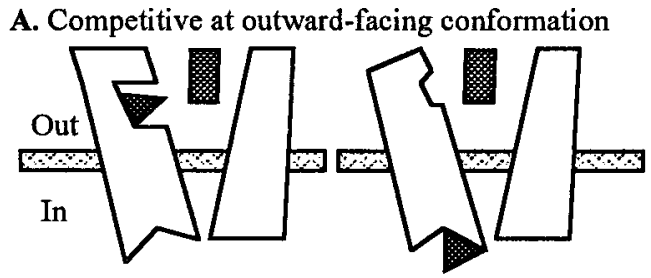

\section{B. Competitive at inward-facing conformation}
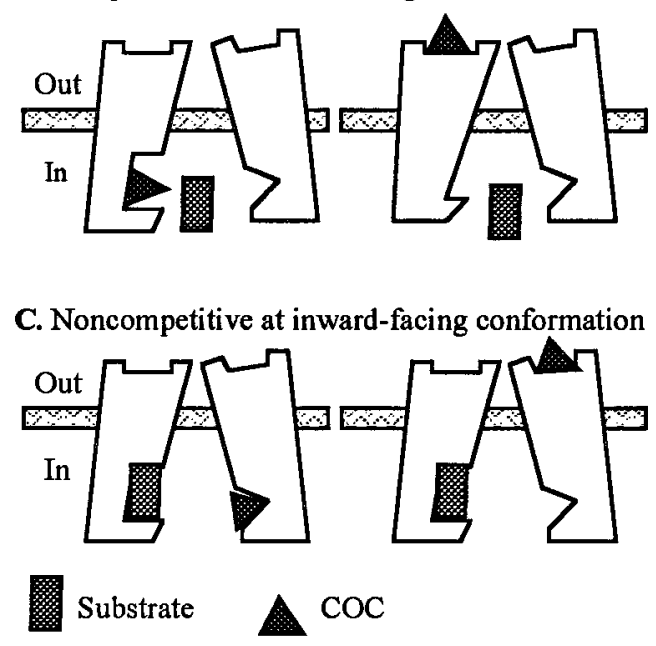

Figure 10. Illustration of the models for interactions of cocaine with different conformations of the hNET. $A$, Competitive interaction at the outward-facing conformation. Cocaine could bind the outward-facing conformation from either outside (left) or inside (right). The binding of cocaine prevents the binding of external DA. $B$, Competitive interaction at the inward-facing conformation. Cocaine could bind the inward-facing conformation from either inside (left) or outside (right). The binding of cocaine prevents the binding of internal DA. $C$, Noncompetitive interaction at the inward-facing conformation. Cocaine could bind the inwardfacing conformation from either inside (left) or outside (right). The binding of cocaine does not prevent the binding of internal DA.

\section{DISCUSSION}

In the present study, the uphill inward transport of external DA, the acceleration of outward transport of internal DA by external substrates, and the lack of inhibition of inward transport by high concentrations of intracellular substrates, are compatible with an alternating access transporter model (Stein, 1986; Rudnick et al., 1997). Thus, kinetic analysis derived from this model was used to address the inhibition mechanism of cocaine at the hNET. The results strongly support a competitive action of cocaine at the outward-facing conformation of the hNET.

In uptake assays, if cocaine is a competitive hNET inhibitor at inward-facing conformation only (Fig. 10B, either left or right) or at both inward-facing and outward-facing conformations, it should show a noncompetitive or mixed inhibition pattern on the zero trans uptake of the external DA, because the external DA could not displace an inhibitor bound to the inward-facing hNET. Furthermore, the inhibition should be weakened by internal substrates displacing the inhibitor from the inward-facing conformation. Finally, the inhibition kinetics would vary with the amount of the inhibitor binding the inward-facing conformation from inside. In the last case, the binding amount of intracellular cocaine could be increased by allowing more cocaine to enter the cell through longer incubation or by enhancing the binding affinity of intracellular cocaine through elevating the intracellular $\left[\mathrm{Na}^{+}\right]$with ouabain. None of the above-mentioned events hap- pened in our study. The inhibition by cocaine of DA uptake appeared entirely competitive, which was not modified by a change in the intracellular concentration of substrate, cocaine, or $\mathrm{Na}^{+}$.

The competitive inhibition by cocaine of DA uptake shown in the present study agrees with previous NET transport studies using $\left[{ }^{3} \mathrm{H}\right] \mathrm{NE}$ in isolated peripheral tissues (Graefe and Bönisch, 1988) but differs from DAT transport studies using the same RDE voltammetry approach in rat brain tissue suspensions (McElvain and Schenk, 1992; Povlock and Schenk, 1997). It should be pointed out that the competitive pattern of cocaine observed in zero trans entry experiments, such as the present DA uptake assay, does not necessarily represent a competitive mechanism at the transporter. This pattern may also be observed for a noncompetitive inhibitor primarily confined to the outward-facing conformation of that transporter (Deves and Krupka, 1989). It has been presumed for catecholamine transporters that the transporter-substrate complex returns faster than the unloaded transporter (Schömig et al., 1988; Zimányi et al., 1989). If the reorientation of the unloaded hNET is the rate-limiting step in the process of DA uptake, the addition of external DA may cause the hNET to be trapped in the inward-facing conformation during initial uptake, out of reach of an inhibitor primarily binding to the outwardfacing conformation of the hNET. As a result, increasing the external concentration of DA could overcome the effect of even a noncompetitive inhibitor, making the pattern competitive. We explored this possibility by testing the effect of internal substrates on cocaine inhibition. Under the assumption that the internal substrate-loaded transporter returns faster than the unloaded one (Stein, 1986), the internal substrate should enhance the cocaine inhibition (if it is caused by a noncompetitive mechanism at the outward-facing conformation) by increasing the availability of the outward-facing conformation of the hNET to cocaine. However, cocaine inhibition was not significantly modified by the internal substrates. Therefore, a noncompetitive mechanism of cocaine at the outward-facing conformation of the hNET seems unlikely.

Because formation of the inward-facing hNET is a necessary prerequisite for the outward transport of internal DA, more direct information about the role of inward-facing hNET in the action of cocaine can be obtained from the efflux assays. The process of $m$-tyramine-induced outward transport consists of two steps (for simplicity, the steps for cotransported ions were not included), according to the simple transporter model. External $m$-tyramine binds to the outward-facing state of the hNET, followed by translocation to the inward-facing state and release of $m$-tyramine inside. Then, internal DA binds, followed by reorientation of the complex and release of DA outside. In the hNETexpressing non-neuronal cells devoid of exocytotic release and vesicular storage of internal amines, the $m$-tyramine-induced DA efflux is most likely related to the above process. This idea is reinforced by the similarity between the $K_{\mathrm{m}}$ of $m$-tyramine for inducing DA efflux and its $K_{\mathrm{i}}$ for inhibiting DA uptake, as well as by the one-phase Hill slopes for the concentration-response curves of $m$-tyramine-induced DA efflux.

In the present study, cocaine inhibited $m$-tyramine-induced DA efflux noncompetitively relative to intracellular DA, but competitively relative to extracellular $m$-tyramine. The results are consistent with a predominant binding of cocaine at the outwardfacing form of the hNET that is inaccessible to internal DA but accessible to the external $m$-tyramine. Consequently, cocaine could reduce the inward transport of $m$-tyramine and, thereby, the amount of inward-facing hNET available for the internal DA, 
resulting in a reduction in $V_{\max }$ relative to $[\mathrm{DA}]_{\mathrm{i}}$; but it could not displace DA from the inward-facing hNET, allowing an unchanged $K_{\mathrm{m}}$ relative to [DA $]_{\mathrm{i}}$. In addition, the higher $K_{\mathrm{i}}$ of cocaine for inhibiting the efflux may be partly caused by its inability to directly prevent the binding of intracellular DA to the inwardfacing conformation.

At least two other interpretations could be raised for the apparently noncompetitive pattern of cocaine inhibition on $m$-tyramine-induced DA efflux with respect to intracellular DA. First, cocaine could quickly diffuse into the cell and bind to a DA-bound inward-facing form of the hNET (Fig. 10C, left). Second, external cocaine and internal DA could simultaneously bind to the inward-facing form, one from each compartment (Fig. $10 C$, right). In both cases, the inhibition by cocaine of $m$-tyramineinduced DA efflux should have shown mixed competitive and noncompetitive patterns relative to extracellular $m$-tyramine, because the external $m$-tyramine displaced only cocaine bound to the outward-facing hNET, not that bound to the inward-facing hNET. However, increasing the external concentration of $m$-tyramine competitively attenuated the inhibition by cocaine of the DA efflux, questioning noncompetitive action of cocaine at the inward-facing conformation.

The higher $K_{\mathrm{m}}$ for outward transport of internal DA may be related to a lower binding affinity of internal DA for the hNET caused by a different conformation or caused by the unfavorable ionic composition of the intracellular side or a slower return rate constant for the loaded hNET. It is unclear whether DA could bind to negatively charged proteins or get trapped in acidic compartments within the cell. If this occurs, it would lower the free concentration of intracellular DA, leading to an overestimation of the $K_{\mathrm{m}}$.

In a different approach, we measured $m$-tyramine uptake and accompanying DA efflux simultaneously. This approach allowed us to investigate the conformational requirement of the transporter of cocaine even without knowledge of its inhibitory nature. Two observations from this experiment rule out the possibility that cocaine may act at the inward-facing conformation of the hNET. First, in contrast to a shift in the DA efflux $/ m$-tyramine uptake ratio curve predicted from the putative interactions between cocaine and internal DA at inward-facing conformation, cocaine did not change the shape and position of the ratio curve across a wide range of $[\mathrm{DA}]_{\mathrm{i}}$. Second, the $\mathrm{IC}_{50}$ value for cocaine to inhibit $m$-tyramine-induced $\mathrm{DA}$ efflux is similar to the $\mathrm{IC}_{50}$ value for it to inhibit $m$-tyramine uptake. Both observations also suggest that cocaine inhibits $m$-tyramine-induced DA efflux solely by inhibiting the inward transport of $m$-tyramine.

Although the kinetics of inhibition can reveal which conformation cocaine attacks, it does not indicate the exact location of the cocaine-binding site, i.e., outside or inside face of the membrane. Our data seem in favor of the binding of cocaine at the outside face of the membrane. This is based on an assumption that less cocaine may enter the cell during the first $15 \mathrm{sec}$ than 6 min and the fact that a 6 min preincubation of cells with cocaine failed to significantly enhance the inhibitory effect of cocaine on inward or outward transport. However, because cocaine is actually a lipophilic weak base entering the cell quickly, the observed failure may also be simply caused by the possibility that cocaine enters cells fast enough to reach a significant intracellular concentration in less than a few seconds.

One mechanism underlying the lack of action of cocaine at the inward-facing conformation may be that the low $\left[\mathrm{Na}^{+}\right]$and high $\left[\mathrm{K}^{+}\right]$inside the cell greatly impair the binding affinity of internal cocaine to the hNET, as has been indicated for the binding of cocaine analogs to the DAT (Chen et al., 1997). Thus, the intracellular concentration of cocaine, although perhaps higher than outside, may be far below its $K_{\mathrm{i}}$ for inhibiting inward-facing hNET and could not compete with the extremely high concentration of internal DA for the inward-facing hNET. If this possibility stands, cocaine might show an apparently noncompetitive component in its inhibition on amine uptake by the NE terminals, because the axoplasm concentration of substrates in NE terminals may be much lower than observed in the LLC-hNET cells. Nevertheless, other mechanisms may also play a role, because elevation of intracellular $\left[\mathrm{Na}^{+}\right]$with ouabain failed to change the inhibition profile of cocaine on DA uptake. In this context, discrete regions of the hNET may be required for the generation of the outwardfacing and inward-facing conformations so that the inward-facing hNET does not form a binding pocket to incorporate cocaine.

The asymmetrical inhibition feature of cocaine is of importance in several respects. First, it may be useful for dissecting conformational changes during the transport cycle, in particular, when the transporter is exposed to alterations in the membrane potential, the ionic gradient, and $\mathrm{pH}$, as well as site-directed mutagenesis. Second, kinetic analysis of interactions of cocaine with other inhibitors at the hNET may be helpful for exploring the conformation specificity of the latter compounds. Third, identification of the incorporation sites of cocaine analogs within the primary sequence may lend insights into domains exposed in outward-facing conformation of the hNET. A combination of structural and kinetic data will be necessary to establish a comprehensive understanding of the transporter mechanism and its inhibition.

\section{REFERENCES}

Bönisch H, Brüss M (1994) The noradrenaline transporter of the neuronal plasma membrane. Ann NY Acad Sci 733:193-202.

Burnette WB, Bailey MD, Kukoyi S, Blakely RD, Trowbridge CG, Justice Jr JB (1996) Human norepinephrine transporter kinetics using rotating disk electrode voltammetry. Anal Chem 68:2932-2938.

Calligaro DO, Eldefrawi ME (1987) Central and peripheral cocaine receptors. J Pharmacol Exp Ther 243:61-68.

Chen NH, Reith MEA (1994) Effect of locally applied cocaine, lidocaine, and various uptake blockers on monoamine transmission in the ventral tegmental area of freely moving rats: a microdialysis study on monoamine interactions. J Neurochem 63:1701-1703.

Chen NH, Reith MEA (1995) Autoregulation and monoamine interactions in the ventral tegmental area in the absence and presence of cocaine: a microdialysis study in freely moving rats. J Pharmacol Exp Ther 271:1597-1610.

Chen NH, Ding JH, Wang YL, Reith MEA (1997) Modeling of the interaction of $\mathrm{Na}^{+}$and $\mathrm{K}^{+}$with the binding of the cocaine analog $\left[{ }^{125} \mathrm{I}\right] 3 \beta$-(iodophenyl)tropan- $2 \beta$-carboxylic acid isopropyl ester to the dopamine transporter. J Neurochem 68:1968-1981.

Chen NH, Trowbridge CG, Justice Jr JB (1998) Voltammetric studies on mechanisms of dopamine efflux in the presence of substrates and cocaine from cells expressing human norepinephrine transporter. J Neurochem 71:653-665.

Devés R, Krupka RM (1989) Inhibition kinetics of carrier systems. Methods Enzymol 171:113-133.

Eshleman AJ, Stewart E, Evenson AK, Mason JN, Blakely RD, Janowsky A, Neve KA (1997) Metabolism of catecholamines by catechol- $O$ methyltransferase in cells expressing recombinant catecholamine transporters. J Neurochem 69:1459-1466.

Graefe K-H, Fuchs G (1979) On the mechanism of neuronal efflux of axoplasmic ${ }^{3} \mathrm{H}$-noradrenaline. In: Catecholamines: basic and clinical frontiers (Usdin E, Kopin IJ, Barchas J, eds) pp 268-270. New York: Pergamon.

Graefe K-H, Bönisch H (1988) The transport of amines across the axonal membranes of noradrenergic and dopaminergic neurons. In: Catecholamines I (Trendelenbury U, Weiner N, eds) pp 193-245. New York: Sringer-Verlag. 
Gu H, Wall S, Rudnick G (1994) Stable expression of biogenic amine transporters reveals differences in inhibitor sensitivity, kinetics, and ion dependence. J Biol Chem 269:7124-7130.

Gu H, Wall SC, Rudnick G (1996) Ion coupling stoichiometry for the norepinephrine transporter in membrane vesicles from stably transfected cells. J Biol Chem 271:6911-6916.

Justice Jr JB, Reed B (1997) Dual electrode characterization of induced efflux of dopamine by $m$-tyramine via the norepinephrine transporter. Soc Neurosci Abstr 23:695.

Justice Jr JB, Danek KS, Kable JW, Barker EL, Blakely RD (1998) Voltammetric approaches to kinetics and mechanism of the norepinephrine transporter. Adv Pharmacol 42:191-194.

Krueger BK (1990) Kinetics and block of dopamine uptake in synaptosomes from rat caudate nucleus. J Neurochem 55:260-267.

Krupka RM, Devés R (1983) Kinetics of inhibition of transport systems. Int Rev Cytol 84:303-352.

Langeloh A, Bönisch H, Trendelenburg U (1987) The mechanism of the ${ }^{3} \mathrm{H}$-noradrenaline releasing effect of various substrates of uptake: multifactorial induction of outward transport. Naunyn Schmiedebergs Arch Pharmacol 336:602-610.

Levi G, Raiteri M (1993) Carrier-mediated release of neurotransmitters. Trends Neurosci 16:415-419.

Masahiko T, Groshan K, Blakely RD, Richelson E (1997) Pharmacological profile of antidepressants and related compounds at human monoamine transporters. Eur J Pharmacol 340:249-258.

McElvain JS, Schenk JO (1992) A multisubstrate mechanism of striatal dopamine uptake and its inhibition by cocaine. J Neurochem 43:2189-2199.
Pacholczyk T, Blakely RD, Amara SG (1991) Expression cloning of a cocaine- and antidepressant-sensitive human noradrenaline transporter. Nature 350:350-354.

Povlock SL, Schenk JO (1997) A multisubstrate kinetic mechanism of dopamine transport in the nucleus accumbens and its inhibition by cocaine. J Neurochem 69:1093-1105.

Rudnick G (1997) Mechanisms of biogenic amine neurotransmitter transporters. In: Neurotransmitter transporters: structure, function, and regulation (Reith MEA, ed). pp 73-100. Totowa, NJ: Humana.

Schömig K, Körber M, Bönisch H (1988) Kinetic evidence for a common binding site for substrates and inhibitors of the neuronal noradrenaline carrier. Naunyn Schmiedebergs Arch Pharmacol 337:626-632.

Sershen H, Reith MEA, Lajtha A (1982) Comparison of the properties of central and peripheral binding sites for cocaine. Neuropharmacology 21:469-474.

Sulzer D, Rayport S (1990) Amphetamine and other psychostimulants reduce $\mathrm{pH}$ gradients in midbrain dopaminergic neurons and chromaffin granules: a mechanism of action. Neuron 5:797-808.

Stein WD (1986) Transport and diffusion across cell membranes. San Diego: Academic.

Wheeler DD, Edwards AM, Chapman BM, Ondo JG (1994) Effects of cocaine on sodium dependent dopamine uptake in rat striatal synaptosomes. Neurochem Res 19:49-56.

Zimányi I, Lajtha A, Reith MEA (1989) Comparison of characteristics of dopamine uptake and mazindol binding in mouse striatum. Naunyn Schmiedebergs Arch Pharmacol 340:626-632. 